\title{
Transcriptome profiling implicated in beneficiary actions of kimchi extracts against Helicobacter pylori infection
}

\author{
Jong-Min Park, ${ }^{1}$ Young-Min Han, ${ }^{2}$ Ji-Young Oh, ${ }^{3}$ Dong-Yoon Lee, ${ }^{3}$ Seung-Hye Choi, ${ }^{3}$ and Ki-Baik Hahm ${ }^{4,5, *}$ \\ 'Daejeon University School of Oriental Medicine, Daejeon, 34520, Korea \\ ${ }^{2}$ Seoul Center, Korea Basic Science Institute, Seoul, 02456, Korea \\ ${ }^{3} \mathrm{CJ}$ Food Research Center, Suwon, 16471, Korea \\ ${ }^{4} \mathrm{CHA}$ Cancer Preventive Research Center, CHA Bio Complex, Pangyo, 13497, Korea \\ ${ }^{5}$ Medpacto Research Institute, Medpacto, Seoul, 06668, Korea
}

(Received 14 July, 2020; Accepted 15 November, 2020)

\begin{abstract}
Dietary intervention to prevent Helicobacter pylori ( $H$. pylori)gastric cancer might be ideal because of no risk of bacterial resistance, safety, and rejuvenating action of atrophic gastritis. We have published data about the potential of fermented kimchi as nutritional approach for $\boldsymbol{H}$. pylori. Hence recent advances in RNAseq analysis lead us to investigate the transcriptome analysis to explain these beneficiary actions of kimchi. gastric cells were infected with either $\boldsymbol{H}$. pylori or $\boldsymbol{H}$. pylori plus kimchi. 943 genes were identified as significantly increased or decreased genes according to $H$. pylori infection and 68 genes as significantly changed between $H$. pylori infection and $H$. pylori plus kimchi $(p<0.05)$. Gene classification and Medline database showed DLL4, FGF18, PTPRN, SLC7A11, CHAC1, FGF21, ASAN, CTH, and CREBRF were identified as significantly increased after $\boldsymbol{H}$. pylori, but significantly decreased with kimchi and NEO1, CLDN8, KLRG1, and IGFBP1 were identified as significantly decreased after $H$. pylori, but increased with kimchi. After KEGG and STRING-GO analysis, oxidative stress, ER stress, cell adhesion, and apoptosis genes were up-regulated with $\boldsymbol{H}$. pylori infection but downregulated with kimchi, whereas tissue regeneration, cellular antioxidative response, and anti-inflammation genes were reversely regulated with kimchi $(p<0.01)$. Conclusively, transcriptomes of $H$. pylori plus kimchi showed significant biological actions.
\end{abstract}

Key Words: H. pylori, RNAseq, transcriptome, biomarker, kimchi

R esearchers unanimously agreed that RNA sequencing (RNAseq) and bioinformatics analysis has introduced exciting opportunities to either biomedical or clinical researches as the "go-to technology" producing high-throughput gene expression profiling, more sensitive than microarray platform, very robust, rather precise, and highly quantitative, ${ }^{(1-3)}$ by which RNAseq analysis is being used to study the dynamics and complexity of eukaryotic transcriptomes, giving new biological insights into the active genome, fulfilling "seeing is believing". (3)

Kimchi is a traditional Korean fermented healthy food featured with profuse probiotics through lactic acid fermentation initiated by red pepper, high levels of phytochemicals, vitamins, minerals, and dietary fibers. ${ }^{(4)}$ Though kimchi is a salt containing food, can be misunderstood as procarcinogen food, a well-designed case-control study revealed kimchi significantly decreased the risk of gastric cancer. ${ }^{(5-7)}$ Therefore, as experienced in western countries that yogurt and other fermented milk products had been important sources for probiotics, fermented kimchi is defined as "probiotic food" in Korea because it contains myriad types of probiotic lactobacillus, L. plantarum as a representative probiotic strain, in which red pepper powder played significant contribution to fermentation. ${ }^{(8,9)}$ Our research group have published that kimchi can be improved into cancer preventive food factor through adding more gradients, so called "cancer preventive kimchi" (abbreviated "cpkimchi"). ${ }^{(10,11)}$

Under the hypothesis that dietary intervention of fermented cpkimchi can prevent $H$. pylori-associated gastric cancer in mice model, long-term intervention of cpkimchi showed significant preventive effects of $H$. pylori-induced gastric cancer either through the rejuvenation of $H$. pylori-associated precancerous atrophic gastritis or blocking gastric tumorigenesis, for instances, STAT3 inhibition, 15-PGDH induction, and inhition of IL-6/ IL-6R/JAK. ${ }^{(11-14)}$ In order to explore transcriptome analysis implicated in these cancer preventive actions of kimchi, in the current study, using RNAseq and bioinformatic analysis, we explored gene profiling analyses to document the beneficiary mechanisms of kimchi extracts against $H$. pylori infection and we could discover the contributing core genes to explain cancer preventive actions of kimchi.

\section{Material and Methods}

H. pylori culture. H. pylori strain ATCC 43504 (American Type Culture Collection, CagA+ and VacA s1-m1 type's strain) was used. H. pylori were cultured at $37^{\circ} \mathrm{C}$ in BBL Trypticase soy (TS) agar plate with 5\% sheep blood (TSAII; BD Biosciences, Franklin Lakes, NJ) under microaerophilic condition (BD GasPaK EZ Gas Generating Systems, BD Biosciences) for 3-5 days. The bacteria were harvested in clean TS broth, centrifuged at $3000 \times \mathrm{g}$ for $5 \mathrm{~min}$, and resuspended in the broth at a final concentration of $10^{9}$ colony-forming units (CFUs) $/ \mathrm{ml}$.

Kimchi preparation and extracts for in vitro experiment. Kimchi preparation was based on the standardized kimchi recipe (skimchi) in CJ Food Research Center, Suwon, Korea. First of all, skimchi is made of birned baechu cabbage (a kind of Chinese cabbage), red pepper powders, garlic, ginger, anchovy juice, sliced redish, green onion, some sugar, then fermented for some periods yielding lactobacillus like L. plantarum. In addition to these ingredients necessary for skimchi production, additional supplements such as mustard leaf, Chinese pepper, pear, mushroom, and sea tangle juice instead of anchovy juice were included in cancer preventive kimchi (cpkimchi). In order to treat to cell, kimchi was freeze-dried and grounded into a

*To whom correspondence should be addressed.

E-mail: hahmkb@hotmail.com 
fine powder. The kimchi powder underwent an extraction process with 20 times of methanol by stirring overnight. Finally, the kimchi methanol extracts were concentrated by heat evaporation (Büchi Rotavapor RE 111; BÜCHI, Flawil, Switzerland) and stored at $4^{\circ} \mathrm{C}$. skimchi and cpkimchi extracts was dissolved into $2.5 \mathrm{mg} / \mathrm{ml}$ in order to execute in vitro experiment.

Cell culture. AGS cells were purchased from ATCC (Manassas, VA), where the cells were properly stored and routinely authenticated (including DNA fingerprinting). After resuscitation in our lab, all the cells were used no longer than 6 months. AGS cells were cultured in RPMI-1640 medium (Gibco BRL, Gaithersburg, MD). All mediums supplemented with $10 \%$ fetal bovine serum (Gibco BRL) at $37^{\circ} \mathrm{C}$ in $5 \% \mathrm{CO}_{2}$. AGS cells were pretreated with kimchi $(5 \mu \mathrm{g} / \mathrm{ml})$ for $1 \mathrm{~h}$ and stimulated with $H$. pylori [100 multiplicity of infection (MOI)] for $24 \mathrm{~h}$. The control group was loaded with the same concentration of the dissolving media of DMSO.

RNA isolation and RNAseq. Total RNA was isolated using Trizol reagent (Invitrogen Life Technologies, Carlsbad, CA). RNA quality was assessed by Agilent 2100 bioanalyzer using the RNA 6000 Nano Chip (Agilent Technologies, Amstelveen, The Netherlands), and RNA quantification was performed using ND-2000 Spectrophotometer (Thermo Inc., Wilmington, DE). For control and test RNAs, the construction of library was performed using QuantSeq 3'mRNA-Seq Library Prep Kit (Lexogen, Inc., Vienna, Austria) according to the manufacturer's instructions. In brief, each $500 \mathrm{ng}$ total RNA were prepared and an oligo-dT primer containing an Illumina-compatible sequence at its 5'end was hybridized to the RNA and reverse transcription was performed. After degradation of the RNA template, second strand synthesis was initiated by a random primer containing an Illumina-compatible linker sequence at its 5'end. The double-stranded library was purified by using magnetic beads to remove all reaction components. The library was amplified to add the complete adapter sequences required for cluster generation. The finished library is purified from PCR components. High-throughput sequencing was performed as single-end 75 sequencing using NextSeq 500 (Illumina, Inc., San Diego, CA).

Data analysis and pathway analysis. QuantSeq 3'mRNASeq reads were aligned using Bowtie2.(15) Bowtie2 indices were either generated from genome assembly sequence or the representative transcript sequences for aligning to the genome and transcriptome. The alignment file was used for assembling transcripts, estimating their abundances and detecting differential expression of genes. Differentially expressed gene were determined based on counts from unique and multiple alignments using coverage in Bedtools. ${ }^{(16)}$ The RC (Read Count) data were processed based on quantile normalization method using EdgeR within R (R development Core Team, 2016) using Bioconductor. ${ }^{(17)}$ Gene classification was based on searches done by DAVID (http://david.abcc.ncifcrf.gov/) and Medline databases (http://www.ncbi.nlm.nih.gov). ${ }^{(18)}$ Pathway analysis was performed on differentially expressed genes basted on the Kyoto Encyclopedia of Genes and Genome (KEGG) pathway databases. ${ }^{(19)}$

Reverse transcription-polymerase chain reaction. After treatment, the medium was removed by suction, and cells were washed with Dulbecco's PBS twice. RiboEX (500 $\mu 1$; GeneAll, Seoul, Korea) was added to plates that were incubated for 10 min at $4^{\circ} \mathrm{C}$. RiboEX was harvested and placed in a $1.5-\mathrm{ml}$ tube, and $100 \mu \mathrm{l}$ of chloroform was added and gently mixed. After incubation for $10 \mathrm{~min}$ in ice, samples were centrifuged at $10,000 \times g$ for $30 \mathrm{~min}$. Supernatants were extracted and mixed with $200 \mu \mathrm{l}$ of isopropanol, and mixtures were incubated at $4^{\circ} \mathrm{C}$ for $1 \mathrm{~h}$. After centrifuging at $13,000 \times g$ for $30 \mathrm{~min}$, the pellet was washed with $70 \%(\mathrm{v} / \mathrm{v})$ ethanol. After allowing the ethanol to evaporate completely, the pellet was dissolved in $100 \mu \mathrm{l}$ of diethylene pyrocarbonate-treated water (Invitrogen). cDNA was prepared using a reverse transcriptase originating from Murine-Moloney leukemia virus (Promega, Madison, WI), according to the manufacturer's instructions. The polymerase chain reaction (PCR) primers used are shown in Supplemental Table $1 *$. PCR was performed using over 30 cycles of $94^{\circ} \mathrm{C}$ for $20 \mathrm{~s}, 58^{\circ} \mathrm{C}$ for $30 \mathrm{~s}$, and $72^{\circ} \mathrm{C}$ for $45 \mathrm{~s}$. Oligonucleotide primers were purchased from Bioneer (Seoul, Korea).

Statistical analysis. The data are represented as mean $\pm \mathrm{SD}$ of the experiments. Either Student's $t$ test or a two-way analysis of variance with a post-hoc test was performed to determine the differences between the groups using a commercially available program (SPSS 12 for Windows; SPSS Inc., Chicago, IL). The level of significance was 0.05 .

\section{Results}

RNAseq analysis. Previous study under the title that dietary intake of fermented kimchi prevented colitis-associated cancer, ${ }^{(20)}$ fermented kimchi prevented $H$. pylori-associated gastric cancer via rejuvenation of chronic atrophic gastritis, and prevention of $H$. pylori-associated gastric cancer with kimchi consistently showed the efficient cancer preventive effect of dietary intake of fermented kimchi on $H$. pylori-associated gastric tumorigenesis. ${ }^{(10)}$ Therefore, using recent advances in precision medicine, in this study, we performed RNAseq analysis in control cells, cells infected with $H$. pylori, and cells infected with $H$. pylori in the presence of extracts from fermented kimchi (Fig. 1A), for which detailed methods are described above. As results, 943 genes were revealed to be significantly different between AGS cells alone and AGS cells infected with $H$. pylori (100 MOI, 48 h) (Fig. 1B) and 68 genes were revealed to be significantly different between AGS cells infected with $H$. pylori (100 MOI) and AGS cells infected with H. pylori in the presence of fermented kimchi extracts (Fig. 1C). All of discovered genes were categorized according to gene function and status of gene expression, up and down and the analyses were all repeated in triplicate manner, of which analysis was repeated with pooling of samples as validation manner.

Genes category significantly different that elevated with $H$. pylori infection, but significantly decreased with kimchi administration. Figure $2 \mathrm{~A}$ showed heatmap comparing the genes, which were significantly increased after $H$. pylori infection, whereas significantly decreased in the presence of kimchi, signifying that transcriptome analysis revealed the genes implicated in antagonizing genes associated with $H$. pylori infection. As summarized in Fig. 2A, they were genes engaged in intrinsic apoptotic signaling pathway in response to endoplasmic reticulum stress like CEBPB/CHAC1/DDIT3/PPP1R15A, IL-6 signaling pathway genes like CEBPB/FOS/SOS1, genes implicated in endoplasmic reticulum stress (ER stress) like CHOP-C/EBP complex (CEBPB/DDIT3), endoplasmic reticulum unfolded protein response (UPR) including $\mathrm{CTH} /$ FGF21/PPP1R15A/CEBPB/DDIT3, PERK-mediated unfolded protein response like DDIT3/ASNS, genes showing response to toxic substance like FOS/ASNS/SLC7A11, apoptosis genes like CHAC1/DDIT3/BIRC3/PPP1R15A/PTPRH, TNF signaling pathway genes like CEBPB/FOS/BIRC3, and mitogen activated protein kinase (MAPK) signaling pathway genes like DDIT3/FOS/SOS1/FGF21. Using KEGG analysis, a database resource for understanding high-level functions and utilities of the biological system, such as the cell, the organism and the ecosystem, from molecular-level information, especially large-scale molecular datasets generated by genome sequencing and other high-throughput experimental technologies, representational transcriptomic presentations of discovered genes were shown in Fig. 2B (apoptosis related-), Fig. 2C (TNF signaling related-), Fig. 2D (cancer pathway related-), and 


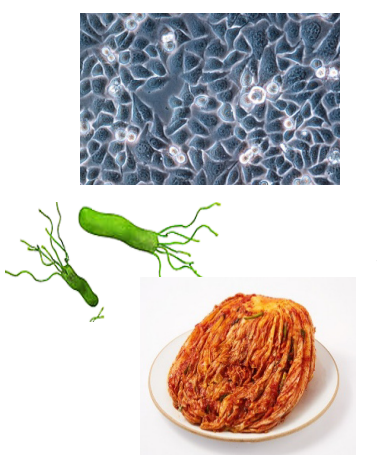

AGS cells alone

$\checkmark$ AGS cells with $H$. pylori

$\checkmark$ AGS cells with $H$. pylori+kimchi (RGM-1/SNU-16 cells repeated)

\section{RNAseq analysis}

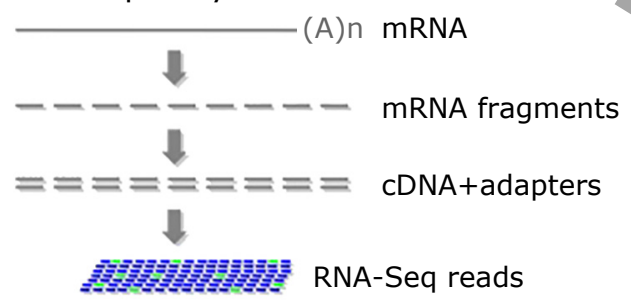

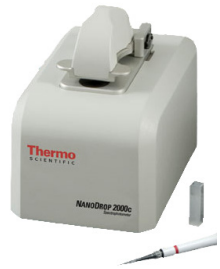

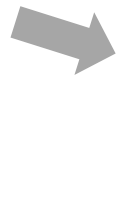

RNA quality \& quantification

\section{NextSeq 500 (Illumina)}

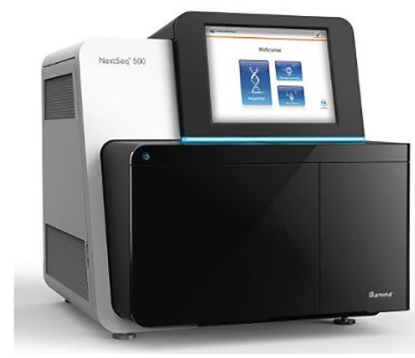

http://www.ncbi.nlm.nih.gov/

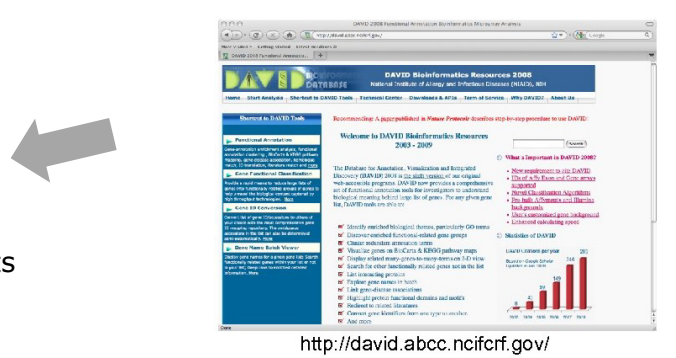

http://david. abcc. ncifcrf.gov/

B

$\%$ of Total significant

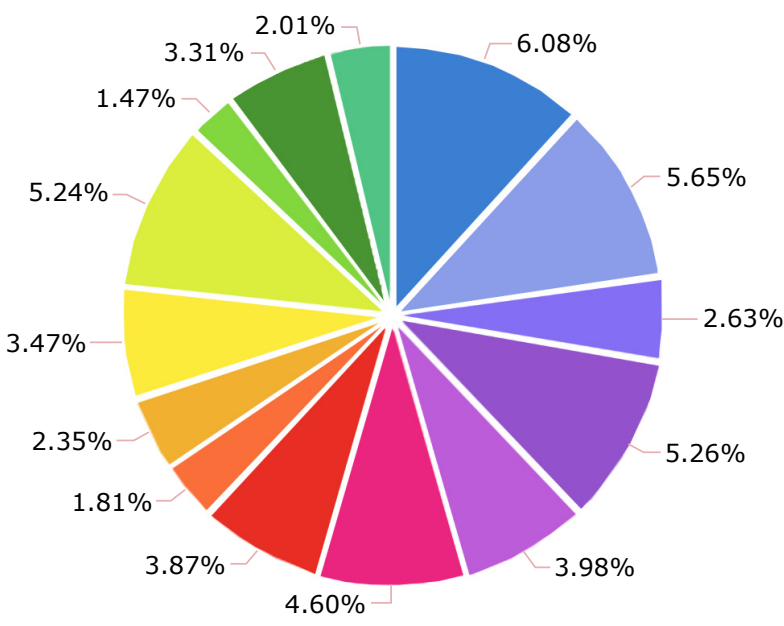

\begin{tabular}{lll} 
Angiogenesis & Cell migration & Inflammatory response \\
Apoptotic process & Cell proliferation & RNA splicing \\
Cell cycle & DNA repair & Secretion \\
Cell death & Extracellular matrix & Cell growth \\
Cell differentiation & Immune response & \\
\hline
\end{tabular}

AGS cells vs AGS cells infected with $H$. pylori

Fig. 1. RNAseq analysis in normal, $H$. pylori infection, and $H$. pylori under kimchi treatment. (A) In vitro AGS cells infected with $H$. pylori, and infected with $H$. pylori in the presence of kimchi, triplicate repeated, NextSeq 500 (Illumina). (B) Gene analyzed according to significantly changed after $H$. pylori, 943 genes included within $p<0.05$. (C) Gene analyzed according to significantly changed after $H$. pylori in the presence of kimchi extracts, 68 genes included within $p<0.05$. 


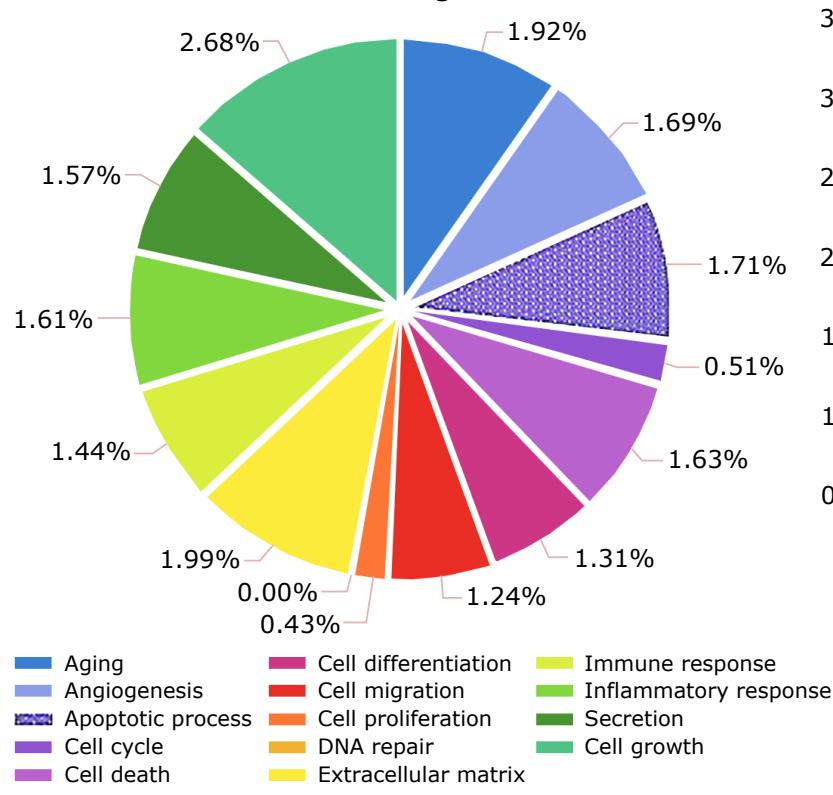

(\%) $\quad$ \% Up significant $\quad \%$ Dn significant

\section{AGS cells infected with $H$. pylori vs AGS cells infected with $H$. pylori and kimchi 68 genes $(p<0.05)$}

Fig. 1. continued.

Fig. 2E (PI3K/AKT signaling related-) were identified, signals elevated after $H$. pylori infection, but significantly downregulated with kimchi extract administration in the presence of H. pylori infection. Search Tool for the Retrieval of Interacting Genes/Proteins (STRING) analysis, a database that comprises established and predicted protein interactions to predict protein interactions among differentially expressed genes, was shown in Supplemental Fig. 1A* (inflammatory and oxidative stress related-), Supplemental Fig. 1B* (intrinsic apoptotic signaling pathway in response to ER stress related-), and Supplemental Fig. 1C* (CHOP-C/EBP complex related). Among discovered genes, core lists of gene, lists of genes called "Kimchi Response Gene Signature" (KRGS) were included in Table 1; List of genes showing significant difference between non-infected vs $H$. pylori infected vs $H$. pylori + kimchi (significantly increased after $H$. pylori, but significantly decreased after $H$. pylori in the presence of kimchi, $p<0.05$ ).

Genes category significantly different that decreased with $H$. pylori infection, but significantly increased with kimchi administration. Figure $3 \mathrm{~A}$ showed heatmap comparing the genes, which were significantly decreased after $H$. pylori infection, whereas significantly increased in the presence of kimchi, signifying that transcriptome analysis revealed the genes implicated in compensating genes associated with $H$. pylori infection. As summarized in Fig. 3A, they were genes engaged in chemokine receptor family like CCR4/CCR7/ACKR4, positive regulation of interferon-gamma production like SLAMF6/LTA/ HLA-DPB1, cell cycle regulator genes like SPDYC/SPDYE4, defense response to gram-positive bacterium like ACP5/LTA/ SSC5D, chemokine receptor activity gene like CCR4/ACKR4, and cytokine-cytokine receptor interaction genes like CCR4/ CCR7/TNFRSF8/LTA. Using KEGG analysis, representational transcriptomic presentations of discovered genes were shown in Fig. 3B (cytokine-cytokine receptor interaction related-), Fig. 3C (endocrine related-), and Fig. 3D (MAPK signaling pathway related-) were identified, signals decreased after $H$. pylori infection, but significantly up-regulated with kimchi extract administration in the presence of $H$. pylori infection. STRING analysis was shown in Supplemental Fig. 2*. Among discovered genes, core lists of gene, lists of genes called "KRGS" were included in Table 2; List of genes showing significant difference between non-infected vs $H$. pylori infected vs $H$. pylori + kimchi (significantly decreased after $H$. pylori, but significantly increased after H. pylori in the presence of kimchi $(p<0.05)$.

GO analysis. KRGS can be summarized as follows; GO analysis shown in Fig. 4A showed $H$. pylori triggered significant bursts of oxidative stress genes, ER stress, increased cell adhesion genes, and inflammatory angiogenesis in gastric epithelial cells, but these genetic explosion was significantly attenuated with kimchi extract, concluding these transcriptomes were categorized as KRGS implicated in down-regulated genes with kimchi to ameliorate $H$. pylori-associated damaging. Based on transcriptomic analysis shown in Table 1, some genes were validated with RT-PCR; delta-like protein 4 (DLL4) and fibroblast growth factor 18 (FGF18) as biomarker for angiogenic factors to promote $H$. pylori-inflammation (Fig. 4B), 4 members of FOS, FOSB, FOSL1, and FOSL2 (FOS), thioredoxin interacting protein 2 (TXNIP), protein tyrosine phosphatase receptor type $\mathrm{N}$ (PTPRN), and cystine/glutamate antiporter (SLC7A11) as oxidative stress imposed by $H$. pylori infection (Fig. 4C), ChaC glutathione specific gammaglutamylcyclotransferase 1 (CHAC1), fibroblast growth factor 21 (FGF21), Asparagine synthetase glutamine-hydrolyzing (ASNS), cystathione gamma-lyase $(\mathrm{CTH})$, and CREB3 regulatory factor (CREBRF) as ER stress genes afforded with $H$. pylori infection (Fig. 4D). On the other hand, GO analysis shown in Fig. 4E showed that $H$. pylori infection led to significant disturbance of tissue regeneration, cellular defense system, and antioxidative defense, but kimchi administration led to significant cytoprotection in this matter. Based on transcriptomic analysis shown in Table 2, some genes were validated with RT-PCR; neogenin 1 (NEO1), claudin8 (CLDN8), killer cell lectin-like 
A

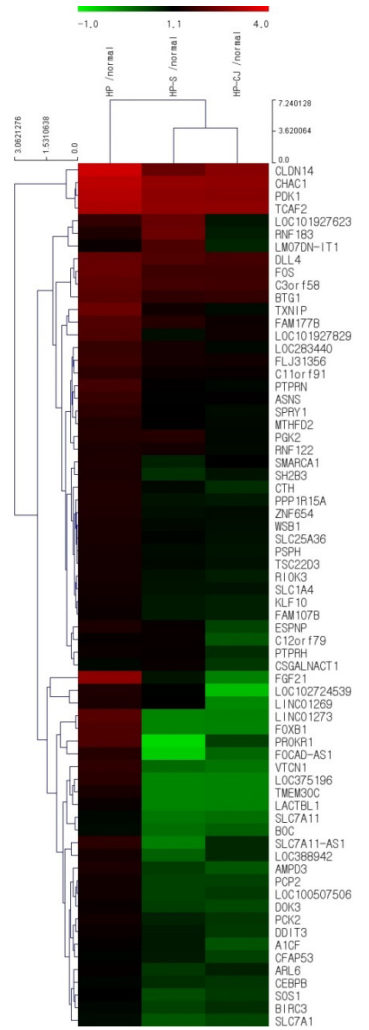

Genes category different significantly between $\boldsymbol{H}$. pylori infection $\uparrow$ and kimchi $\downarrow$

(68 genes, $p<0.05)$

* Intrinsic apoptotic signaling pathway in response to endoplasmic reticulum stress $\rightarrow$ CEBPB/CHAC1/DDIT3/PPP1R15A

* IL-6 signaling pathway $\rightarrow$ CEBPB/FOS/SOS1

* CHOP-C/EBP complex $\rightarrow$ CEBPB/DDIT3

* Endoplasmic reticulum unfolded protein response (UPR) $\rightarrow$ CTH/FGF21/PPP1R15A

* Response to endoplasmic reticulum stress (ER stress) $\rightarrow$ CEBPB/DDIT3/PPP1R15A

* Response to toxic substance $\rightarrow$ FOS/ASNS/SLC7A11

* PERK-mediated unfolded protein response $\rightarrow$ DDIT3/ASNS

* Apoptosis $\rightarrow$ CHAC1/DDIT3/BIRC3/PPP1R15A/PTPRH

* TNF signaling pathway $\rightarrow$ CEBPB/FOS/BIRC3

* MAPK signaling pathway $\rightarrow$ DDIT3/FOS/SOS1/FGF21

\section{B}

APOPTOSIS

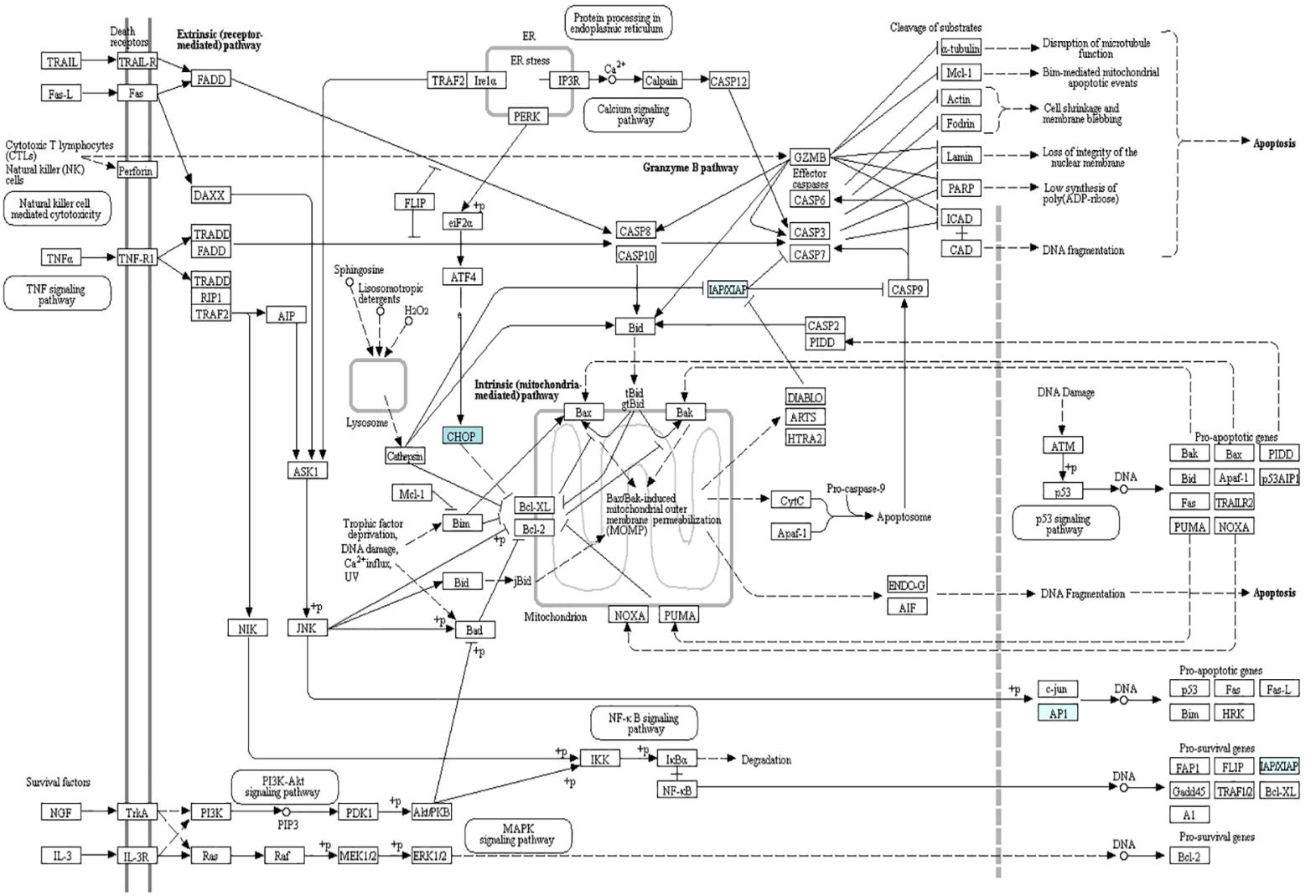

Fig. 2. (A) Heatmap showing significant trend like decreased with H. pylori infection, but increased with co-treatment of kimchi, description of gene category. (B-E) KEGG analysis. 
C TNF SIGNALING PATHWAY
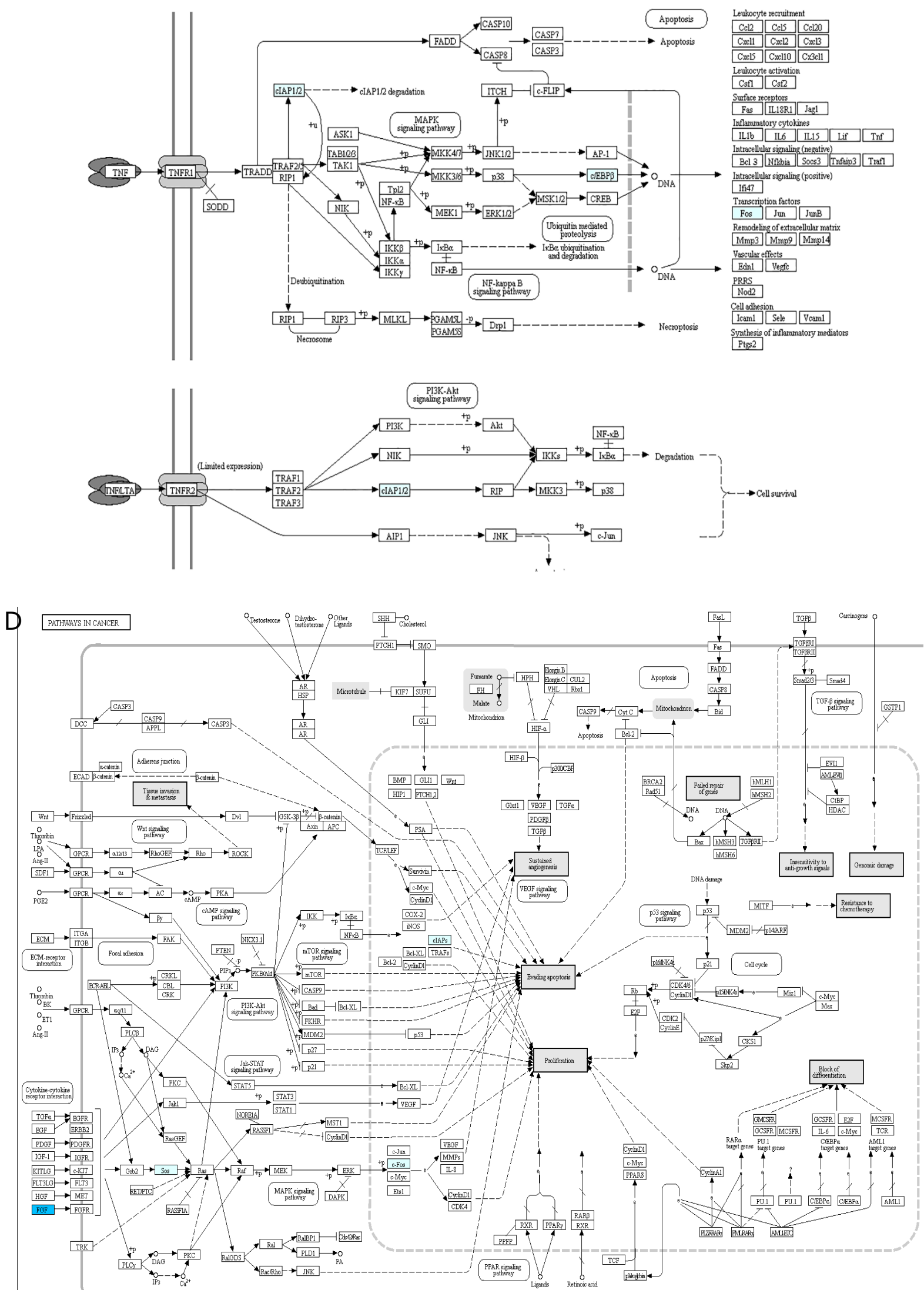

Fig. 2. continued. 


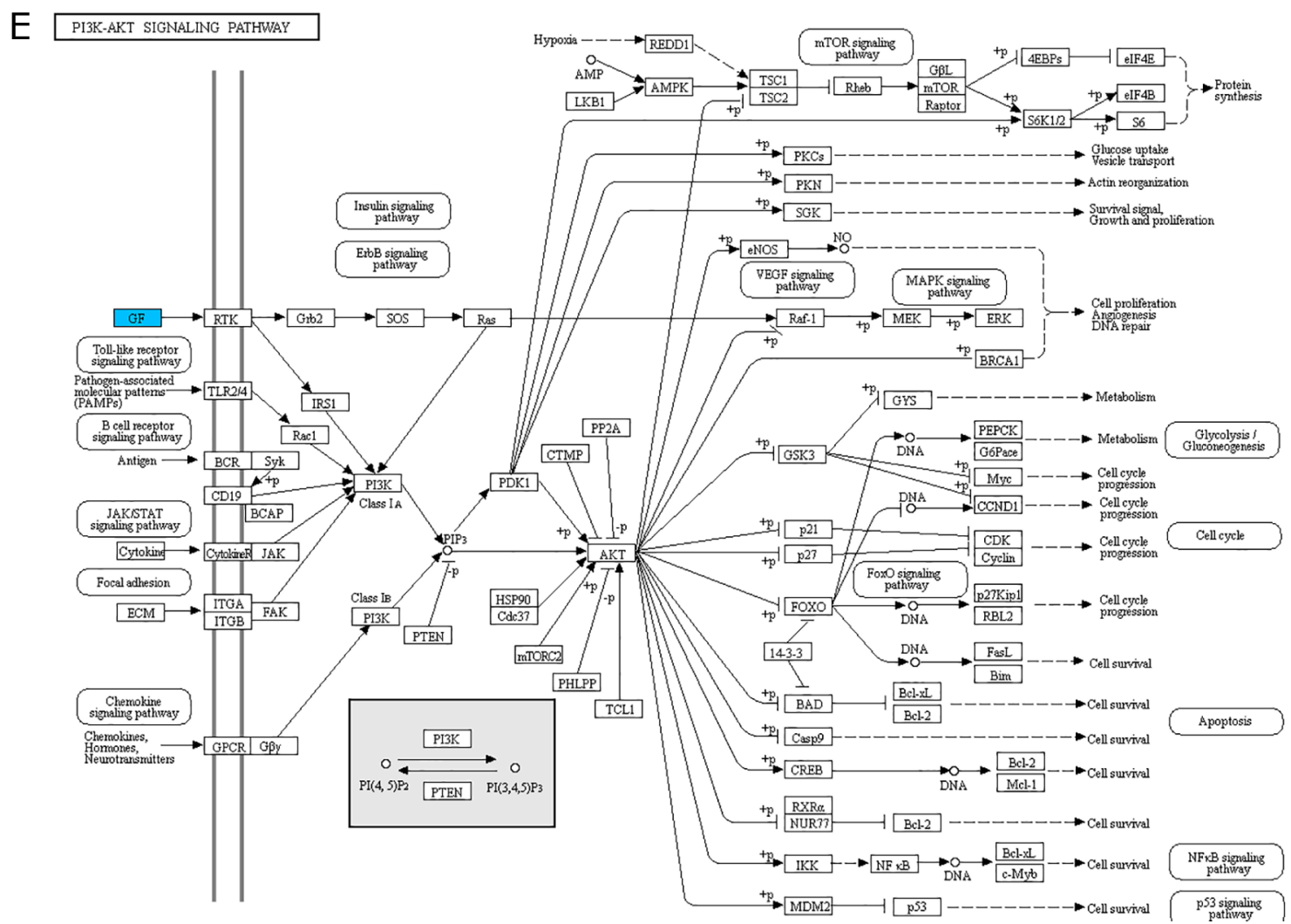

Fig. 2. continued.

receptor G1 (KLRG1), and insulin-like growth factor-binding protein 1 (IGFBP1) (Fig. 4E).

\section{Discussion}

In the current study, we conducted gene profiling analyses of $H$. pylori-infected AGS cells influenced with kimchi extracts administration through RNAseq analysis and determined that ER stress/oxidative stress/apoptosis as well as tissue regenerationrelated genes played a crucial role in dietary contribution of kimchi against $H$. pylori infection after bioinformatic analysis (Fig. 4). Among genetic influences after $H$. pylori infection, we could isolate genes which were elevated after $H$. pylori, but significantly decreased with kimchi and genes which were significantly decreased after $H$. pylori infection, but significantly increased with kimchi $(p<0.01)$. The fact that previous publication that dietary intake of kimchi, especially fermented kimchi, significantly prevented $H$. pylori-associated gastric cancer via the rejuvenation of precancerous atrophic gastritis was also be explained by similar findings drawn from the current investigation increases the significance of current transcriptome analysis. ${ }^{(10)}$ NGS technology has revolutionized genetic and biomedical research.

RNAseq is the use of NGS technology to sequence cDNA (reversed transcribed from RNA) in order to obtain information about RNA. Compared to microarray technology, RNAseq technology offers several obvious advantages. First, RNAseq analysis allows the detection of all isoforms of a gene, even novel ones. Microarray, on the other hand, relies purely on previous knowledge regarding genes to design probes for detection, thus it cannot be used for novel detection. Second, the resolution of microarray usually stays at the gene and exon level, but the resolution of RNAseq can reach the level of a single nucleotide, which allows detection of single nucleotide variance and structural variants, such as small insertions, deletions, alternative splicing, and gene fusion. ${ }^{(21-23)}$ These RNAseq analyses had several advantages over microarrays, to be very robust, more sensitive, highly quantitative, highly reproducible, and highly accurate. Therefore, the findings from the current investigation highlight the implication of dietary, non-microbial, nutritional intervention can be of potential trial for troublesome H. pylori infection beyond simple eradication. We clearly can explain how kimchi can fight against $H$. pylori infection, relieving ER stress, decreasing oxidative stress, alleviating apoptosis, mitigating oncogenic inflammation, and affording rejuvenating and cancer preventive actions in chronic $H$. pylori infection. Conclusively, gene classification DAVID and Medline database showed genes like DLL4, FGF18, PTPRN, SLC7A11, CHAC1, FGF21, ASAN, CTH, and CREBRF were identified as significantly increased after $H$. pylori, but significantly decreased with kimchi, whereas genes like NEO1, CLDN8, KLRG1, and IGFBP 1 were identified as significantly decreased after $H$. pylori, but significantly increased with kimchi.

Detailly inspected with description for discovered gene, genes for ER stress. Subsequent apoptosis, and oxidative stress were all identified as genes which are elevated after $H$. pylori infection, but significantly attenuated in the presence of kimchi (Fig. 2, Supplemental Fig. 1*, and Table 1); ER stress genes including CEBPB/CHAC1/DDIT3/PPP1R15A, IL-6 signaling pathway genes like CEBPB/FOS/SOS1, genes implicated in ER stress complex like CEBPB/DDIT3, UPR genes including CTH/FGF21/PPP1R15A/CEBPB/DDIT31/ASNS, genes showing response to toxic substance like FOS/ASNS/SLC7A11, TNF signaling pathway genes like CEBPB/FOS/BIRC3, and MAPK signaling pathway genes like SOS1/FGF21. Intestinal metaplasia (IM) is an abeerant phenotype arising during $H$. pylori-associated 
Table 1. Lists of KRGS (Kimchi Response Gene Signature)

\begin{tabular}{|c|c|c|c|}
\hline \multicolumn{4}{|c|}{ Average of normalize RC $\left(\log _{2}\right)$} \\
\hline Genes & Non-infected & H. pylori & H. pylori + kimchi \\
\hline CLDN14 & 1 & 3.759 & 3.132 \\
\hline FAM177B & 1 & 2.522 & 1.954 \\
\hline PROKR1 & 1 & 3.872 & 1.850 \\
\hline LOC101927623 & 1 & 2.889 & 2.031 \\
\hline VTCN1 & 1 & 3.399 & 1.183 \\
\hline PGK2 & 1 & 2.083 & 1.756 \\
\hline C12orf79 & 1 & 2.750 & 1.580 \\
\hline CHAC1 & 1 & 1.418 & 1.351 \\
\hline PDK1 & 1 & 1.393 & 1.331 \\
\hline TCAF2 & 1 & 1.462 & 1.412 \\
\hline TXNIP & 1 & 1.241 & 1.104 \\
\hline FOS & 1 & 1.467 & 1.370 \\
\hline DLL4 & 1 & 1.449 & 1.376 \\
\hline C3orf58 & 1 & 1.226 & 1.190 \\
\hline BTG1 & 1 & 1.233 & 1.189 \\
\hline PTPRN & 1 & 1.689 & 1.382 \\
\hline FLJ31356 & 1 & 1.313 & 1.231 \\
\hline TMEMЗОС & 1 & 916.191 & 6.804 \\
\hline LACTBL1 & 1 & 983.274 & 6.804 \\
\hline FGF21 & 1 & 461.62 & 6.808 \\
\hline LINC01273 & 1 & 491.887 & 6.807 \\
\hline FOXB1 & 1 & 744.837 & 6.805 \\
\hline LMO7DN-IT1 & 1 & 251.773 & 162.552 \\
\hline ASNS & 1 & 1.155 & 1.102 \\
\hline C11orf91 & 1 & 1.725 & 1.538 \\
\hline SPRY1 & 1 & 1.199 & 1.123 \\
\hline SLC7A11-AS1 & 1 & 1.259 & 1.126 \\
\hline FOCAD-AS1 & 1 & 1.876 & 1.146 \\
\hline MTHFD2 & 1 & 1.123 & 1.085 \\
\hline PPP1R15A & 1 & 1.125 & 1.078 \\
\hline СTH & 1 & 1.175 & 1.087 \\
\hline ZNF654 & 1 & 1.151 & 1.105 \\
\hline SMARCA1 & 1 & 1.402 & 1.308 \\
\hline RNF183 & 1 & 1.929 & 1.564 \\
\hline SH2B3 & 1 & 1.159 & 1.105 \\
\hline RNF122 & 1 & 1.236 & 1.172 \\
\hline AMPD3 & 1 & 1.291 & 1.078 \\
\hline ESPNP & 1 & 1.321 & 1.125 \\
\hline SLC25A36 & 1 & 1.117 & 1.081 \\
\hline PSPH & 1 & 1.126 & 1.088 \\
\hline RIOK3 & 1 & 1.121 & 1.077 \\
\hline TSC22D3 & 1 & 1.391 & 1.280 \\
\hline PCP2 & 1 & 1.504 & 1.218 \\
\hline PER1 & 1 & 1.149 & 1.215 \\
\hline SLC1A4 & 1 & 1.143 & 1.103 \\
\hline PCK2 & 1 & 1.126 & 1.063 \\
\hline KLF10 & 1 & 1.135 & 1.089 \\
\hline PTPRH & 1 & 1.339 & 1.205 \\
\hline FAM107B & 1 & 1.103 & 1.070 \\
\hline DDIT3 & 1 & 1.129 & 1.067 \\
\hline DOK3 & 1 & 1.206 & 1.085 \\
\hline ARL6 & 1 & 1.166 & 1.117 \\
\hline $\mathrm{A} 1 \mathrm{CF}$ & 1 & 1.736 & 1.259 \\
\hline SOS1 & 1 & 1.095 & 1.054 \\
\hline CFAP53 & 1 & 1.213 & 1.115 \\
\hline CEBPB & 1 & 1.104 & 1.066 \\
\hline CSGALNACT1 & 1 & 1.223 & 1.138 \\
\hline BIRC3 & 1 & 1.134 & 1.092 \\
\hline SLC7A11 & 1 & 1.113 & 1.019 \\
\hline $\mathrm{BOC}$ & 1 & 1.331 & 1.101 \\
\hline SLC7A1 & 1 & 1.085 & 1.043 \\
\hline
\end{tabular}

List of genes showing significant difference between non-infected vs $H$. pylori infected vs $H$. pylori + kimchi (significantly increased after $H$. pylori, but significantly decreased after $H$. pylori in the presence of kimchi, $p<0.05$ ). 
A

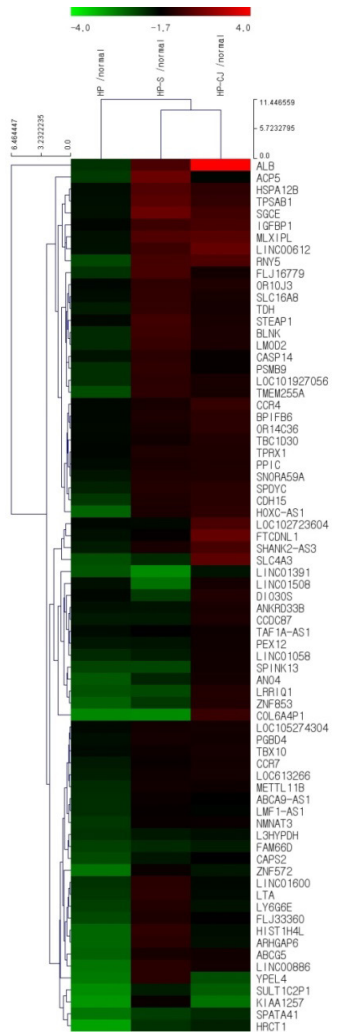

Genes category different significantly between $\boldsymbol{H}$. pylori infection $\downarrow$ and kimchi $\uparrow$

(172 genes, $p<0.05)$

* Chemokine receptor family $\rightarrow$ CCR4/CCR7/ACKR4

* Positive regulation of interferon-gamma production $\rightarrow$ SLAMF6/LTA/HLA-DPB1

* Cell cycle regulator $\rightarrow$ SPDYC/SPDYE4

* Defense response to gram-positive bacterium $\rightarrow$ ACP5/LTA/SSC5D

* Chemokine receptor activity $\rightarrow$ CCR4/ACKR4

* Cytokine-cytokine receptor interaction $\rightarrow$ CCR4/CCR7/TNFRSF8/LTA
B CYTOKINECYYTOKINE RECEPPOR INTRRACTION

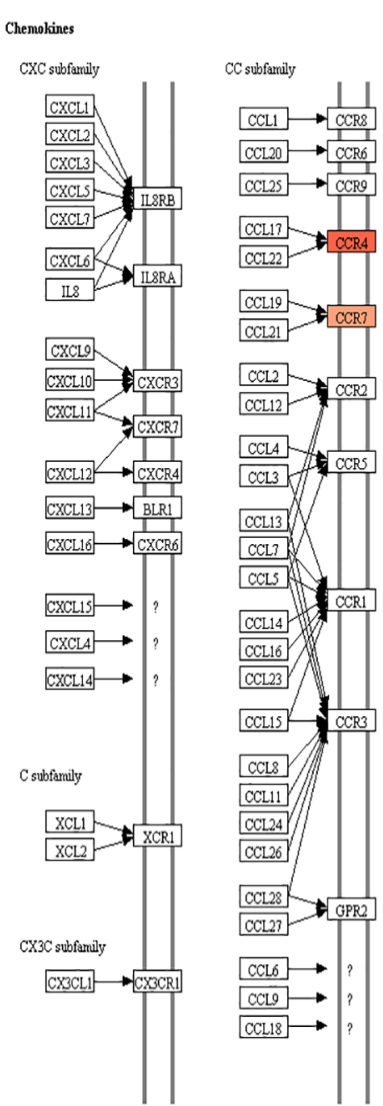

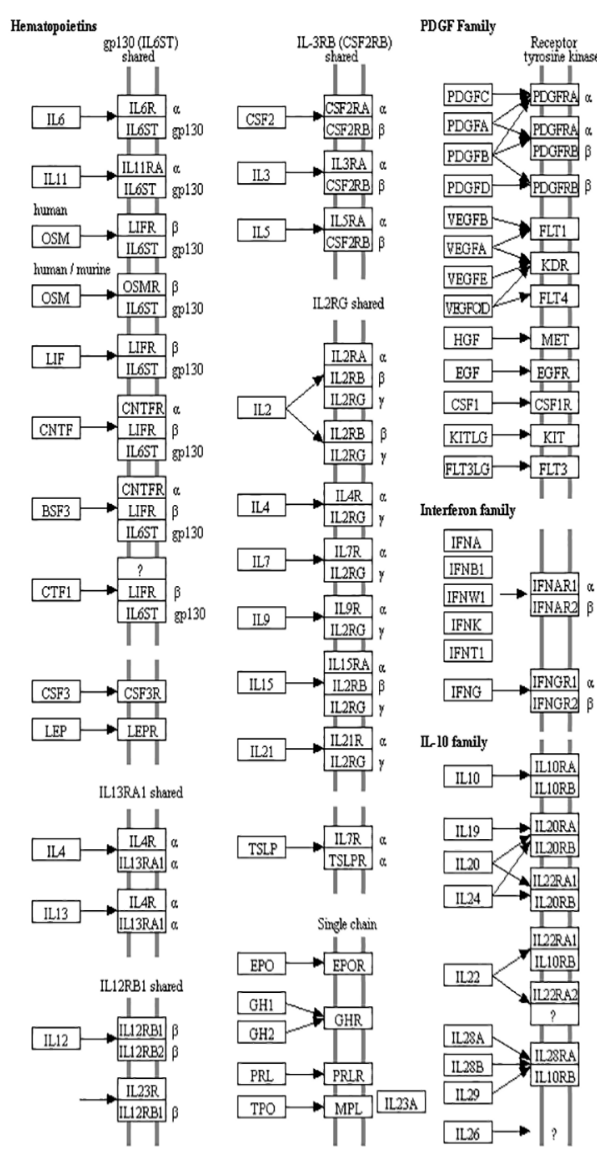
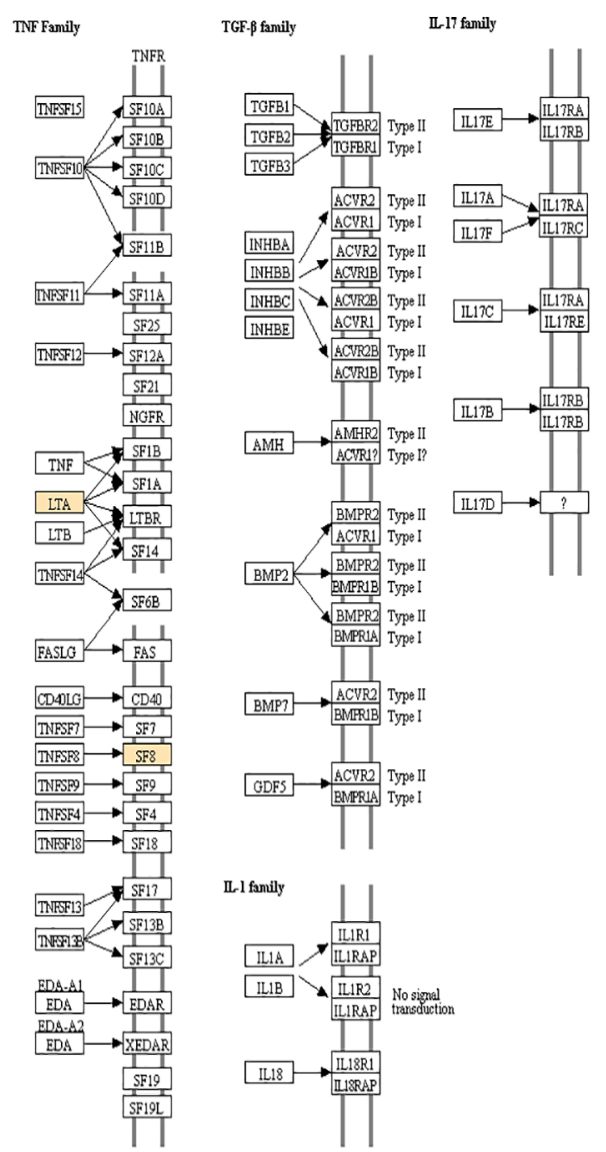

Fig. 3. (A) Heatmap showing significant trend like elevated with $H$. pylori infection, but decreased with co-treatment of kimchi, description of gene category. (B-D) KEGG analysis. 


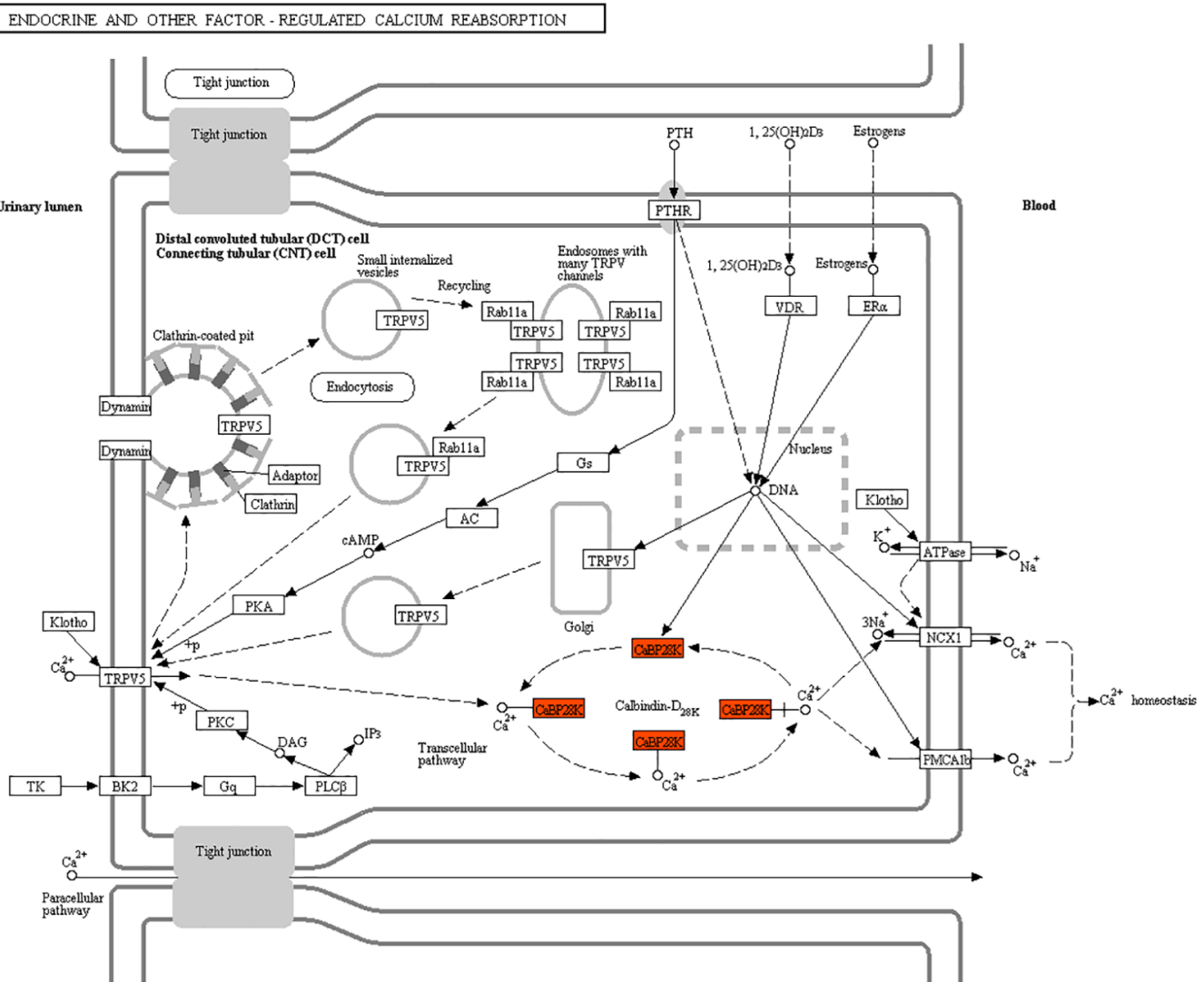

D MAPK SIGNALING PATHWAY

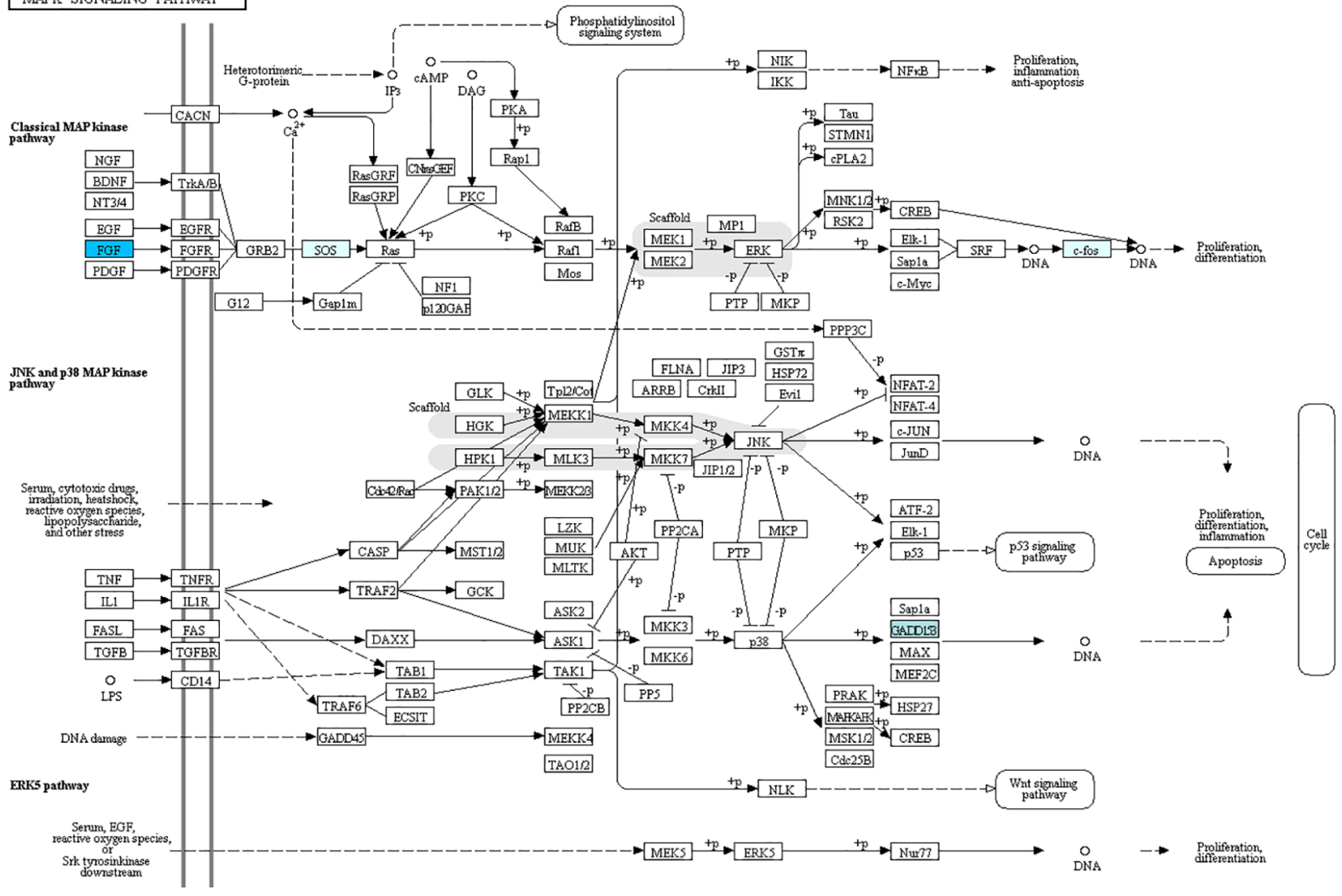

Fig. 3. continued. 
Table 2. Lists of KRGS (Kimchi Response Gene Signature)

\begin{tabular}{|c|c|c|c|}
\hline \multicolumn{4}{|c|}{ Average of normalize RC $\left(\log _{2}\right)$} \\
\hline Genes & Non-infected & H. pylori & H. pylori + kimchi \\
\hline TPRX1 & 1 & 0.006 & 0.449 \\
\hline BPIFB6 & 1 & 0.008 & 0.585 \\
\hline CCR4 & 1 & 0.008 & 0.724 \\
\hline OR10J3 & 1 & 0.008 & 0.447 \\
\hline OR14C36 & 1 & 0.007 & 0.592 \\
\hline ANKRD33B & 1 & 0.008 & 0.397 \\
\hline ABCA9-AS1 & 1 & 0.006 & 0.200 \\
\hline LTA & 1 & 0.008 & 0.194 \\
\hline NMNAT3 & 1 & 0.006 & 0.335 \\
\hline SPINK13 & 1 & 0.006 & 0.441 \\
\hline $\mathrm{TDH}$ & 1 & 0.012 & 0.380 \\
\hline LMOD2 & 1 & 0.011 & 0.479 \\
\hline ALB & 1 & 0.045 & 3.246 \\
\hline ACP5 & 1 & 0.014 & 0.224 \\
\hline RNY5 & 1 & 0.013 & 1.034 \\
\hline TMEM255A & 1 & 0.011 & 0.524 \\
\hline ZNF853 & 1 & 0.012 & 0.635 \\
\hline ABCG5 & 1 & 0.010 & 0.499 \\
\hline YPEL4 & 1 & 0.011 & 0.158 \\
\hline COL6A4P1 & 1 & 0.011 & 0.863 \\
\hline GYG2P1 & 1 & 0.009 & 0.675 \\
\hline MTVR2 & 1 & 0.007 & 0.418 \\
\hline CLDN8 & 1 & 0.009 & 0.567 \\
\hline SYCP1 & 1 & 0.006 & 0.317 \\
\hline SPDYE4 & 1 & 0.005 & 0.343 \\
\hline CLEC9A & 1 & 0.008 & 0.589 \\
\hline HEPACAM2 & 1 & 0.008 & 0.532 \\
\hline OLIG2 & 1 & 0.007 & 0.493 \\
\hline SEBOX & 1 & 0.005 & 0.472 \\
\hline MAS1L & 1 & 0.008 & 0.456 \\
\hline TDH & 1 & 0.012 & 0.380 \\
\hline LMOD2 & 1 & 0.011 & 0.479 \\
\hline ALB & 1 & 0.045 & 3.246 \\
\hline ACP5 & 1 & 0.014 & 0.224 \\
\hline RNY5 & 1 & 0.013 & 1.034 \\
\hline TMEM255A & 1 & 0.011 & 0.524 \\
\hline ZNF853 & 1 & 0.012 & 0.635 \\
\hline ABCG5 & 1 & 0.010 & 0.499 \\
\hline YPEL4 & 1 & 0.011 & 0.158 \\
\hline COL6A4P1 & 1 & 0.011 & 0.863 \\
\hline GYG2P1 & 1 & 0.009 & 0.675 \\
\hline MTVR2 & 1 & 0.007 & 0.418 \\
\hline CLDN8 & 1 & 0.009 & 0.567 \\
\hline SYCP1 & 1 & 0.006 & 0.317 \\
\hline SPDYE4 & 1 & 0.005 & 0.343 \\
\hline CLEC9A & 1 & 0.008 & 0.589 \\
\hline HEPACAM2 & 1 & 0.008 & 0.532 \\
\hline OLIG2 & 1 & 0.007 & 0.493 \\
\hline SEBOX & 1 & 0.005 & 0.472 \\
\hline MAS1L & 1 & 0.008 & 0.456 \\
\hline MLXIPL & 1 & 0.595 & 1.059 \\
\hline LINC01508 & 1 & 0.593 & 0.729 \\
\hline SNORA59A & 1 & 0.448 & 0.700 \\
\hline SHANK2-AS3 & 1 & 0.467 & 0.970 \\
\hline LINC01058 & 1 & 0.461 & 0.659 \\
\hline FLJ16779 & 1 & 0.494 & 0.702 \\
\hline $\mathrm{CDH} 15$ & 1 & 0.556 & 0.842 \\
\hline LY6G6E & 1 & 0.412 & 0.518 \\
\hline CAPS2 & 1 & 0.432 & 0.605 \\
\hline LRRIQ1 & 1 & 0.456 & 0.793 \\
\hline ZNF572 & 1 & 0.560 & 0.697 \\
\hline LINC00886 & 1 & 0.460 & 0.756 \\
\hline SULT1C2P1 & 1 & 0.495 & 0.566 \\
\hline TSPAN32 & 1 & 0.273 & 0.718 \\
\hline
\end{tabular}


Table 2. continued.

\begin{tabular}{|c|c|c|c|}
\hline \multicolumn{4}{|c|}{ Average of normalize RC $\left(\log _{2}\right)$} \\
\hline Genes & Non-infected & H. pylori & H. pylori + kimchi \\
\hline LOC102724434 & 1 & 0.269 & 0.881 \\
\hline SPATA3-AS1 & 1 & 0.246 & 0.457 \\
\hline C11orf53 & 1 & 0.241 & 0.448 \\
\hline RHBDL3 & 1 & 0.210 & 0.549 \\
\hline SGCG & 1 & 0.202 & 0.909 \\
\hline CCM2L & 1 & 0.201 & 0.374 \\
\hline SPDYC & 1 & 0.258 & 0.713 \\
\hline BLNK & 1 & 0.273 & 0.617 \\
\hline METTL11B & 1 & 0.285 & 0.525 \\
\hline LMF1-AS1 & 1 & 0.251 & 0.384 \\
\hline PSMB9 & 1 & 0.251 & 0.464 \\
\hline LINC01600 & 1 & 0.249 & 0.382 \\
\hline FLJ33360 & 1 & 0.247 & 0.482 \\
\hline SLC4A3 & 1 & 0.244 & 1.129 \\
\hline LINC01391 & 1 & 0.163 & 0.366 \\
\hline ANO4 & 1 & 0.139 & 0.569 \\
\hline HOXC-AS1 & 1 & 0.267 & 0.807 \\
\hline HIST1H4L & 1 & 0.244 & 0.477 \\
\hline ARHGAP6 & 1 & 0.277 & 0.493 \\
\hline SPATA41 & 1 & 0.204 & 0.405 \\
\hline KIAA1257 & 1 & 0.140 & 0.235 \\
\hline HRCT1 & 1 & 0.299 & 0.560 \\
\hline ZPBP2 & 1 & 0.013 & 0.710 \\
\hline HLA-DPB1 & 1 & 0.012 & 0.825 \\
\hline LINC01088 & 1 & 0.013 & 0.954 \\
\hline MYBPH & 1 & 0.015 & 1.519 \\
\hline MMP28 & 1 & 0.017 & 1.333 \\
\hline TTC22 & 1 & 0.011 & 0.604 \\
\hline IGFBP1 & 1 & 0.011 & 0.940 \\
\hline SGCE & 1 & 0.018 & 0.886 \\
\hline LINC00612 & 1 & 0.012 & 1.304 \\
\hline FTCDNL1 & 1 & 0.011 & 1.308 \\
\hline MLXIPL & 1 & 0.595 & 1.059 \\
\hline LINC01508 & 1 & 0.593 & 0.729 \\
\hline SNORA59A & 1 & 0.448 & 0.700 \\
\hline SHANK2-AS3 & 1 & 0.467 & 0.970 \\
\hline LINC01058 & 1 & 0.461 & 0.659 \\
\hline FLJ16779 & 1 & 0.494 & 0.702 \\
\hline CDH15 & 1 & 0.556 & 0.842 \\
\hline LY6G6E & 1 & 0.412 & 0.518 \\
\hline CAPS2 & 1 & 0.432 & 0.605 \\
\hline LRRIQ1 & 1 & 0.456 & 0.793 \\
\hline ZNF572 & 1 & 0.560 & 0.697 \\
\hline LINC00886 & 1 & 0.460 & 0.756 \\
\hline SULT1C2P1 & 1 & 0.495 & 0.566 \\
\hline LOC283585 & 1 & 0.278 & 1.021 \\
\hline TSPAN32 & 1 & 0.273 & 0.718 \\
\hline SPATA3-AS1 & 1 & 0.246 & 0.457 \\
\hline C11orf53 & 1 & 0.241 & 0.448 \\
\hline RHBDL3 & 1 & 0.210 & 0.549 \\
\hline SGCG & 1 & 0.202 & 0.909 \\
\hline CCM2L & 1 & 0.201 & 0.374 \\
\hline SPDYC & 1 & 0.258 & 0.713 \\
\hline BLNK & 1 & 0.273 & 0.617 \\
\hline METTL11B & 1 & 0.285 & 0.525 \\
\hline LMF1-AS1 & 1 & 0.251 & 0.384 \\
\hline
\end{tabular}

List of genes showing significant difference between non-infected vs $H$. pylori infected vs $H$. pylori + kimchi (significantly decreased after $H$. pylori, but significantly increased after $H$. pylori in the presence of kimchi, $p<0.05$ ).

carcinogenesis mostly associated with chronic atrophic gastritis (CAG), during which UPR activated by ER stress is prominently observed, ${ }^{(24)}$ leading to conclusion that the UPR induction in the milieu of H. pylori, especially VacA positive, -induced chronic inflammation and IM may promote neoplastic transformation through apoptosis of parietal cells and activation of ER 
A KRGS (kimchi response gene signature)

H. pylori-associated, but kimchi down-regulated

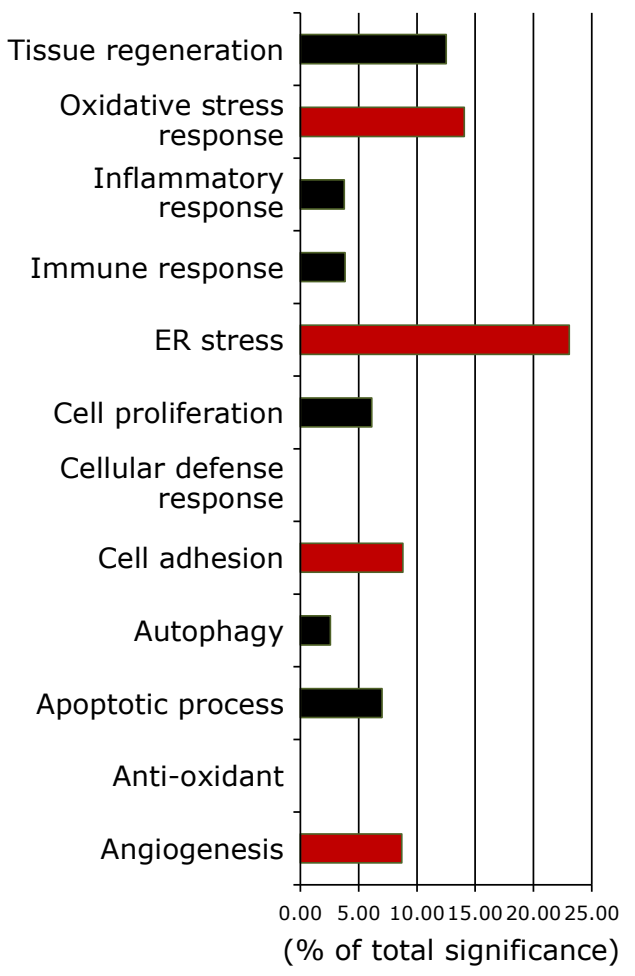

B

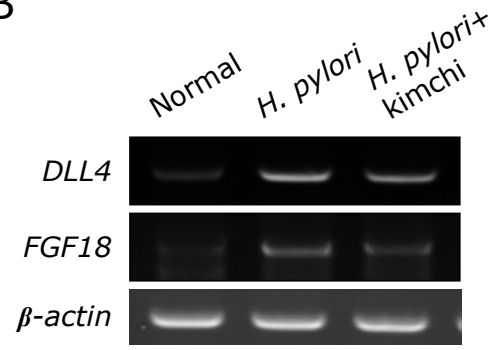

C

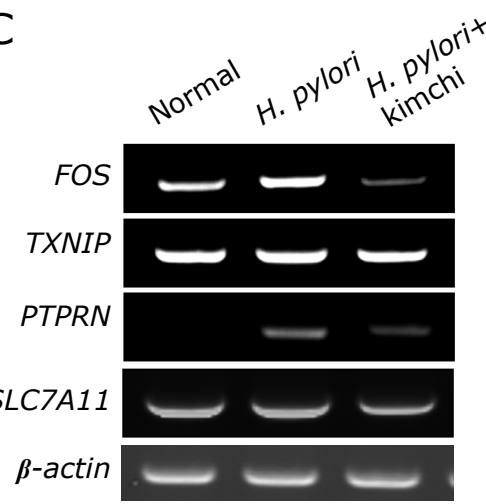

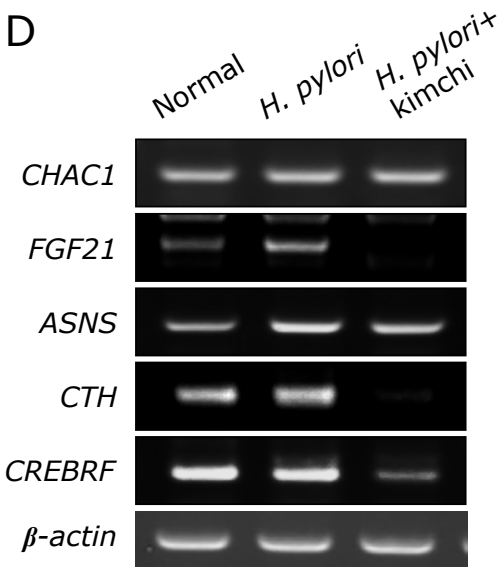

E KRGS (kimchi response gene signature) kimchi up-regulated under $H$. pylori

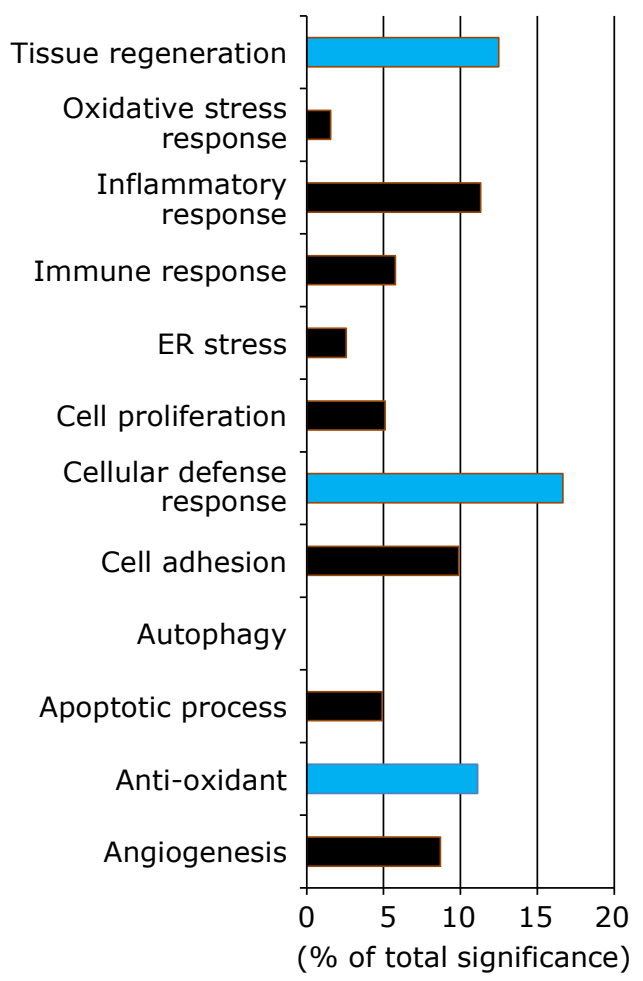

$\mathrm{F}$

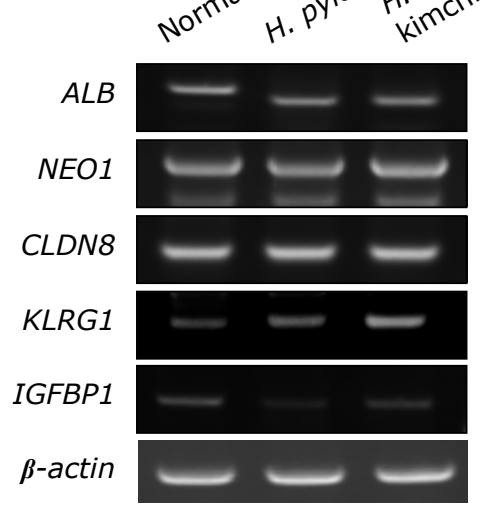

Fig. 4. KRGS. (A) GO analysis of the enrichment of differentially expressed genes between $H$. pylori-associated up-regulated genes, but downregulated with kimchi GO, gene ontology. (B) RT-PCR for DLL4 and FGF18, gene for angiogenesis. (C) RT-PCR for FOS, TXNIP, PTPRN, and SLG7A11, gene for ER stress. (D) RT-PCR for CHAC1, FGF21, ASNS, CTH, and CREBRF, gene for oxidative stress. (E) GO analysis of the enrichment of differentially expressed genes between $H$. pylori-associated down-regulated genes, but up-regulated with kimchi GO, gene ontology. (F) RT-PCR for $A L B, N E O 1, C L D N 8, K L R G 1$, IGFBP, genes in antioxidant, cell adhesion, cell defense, and regeneration. 


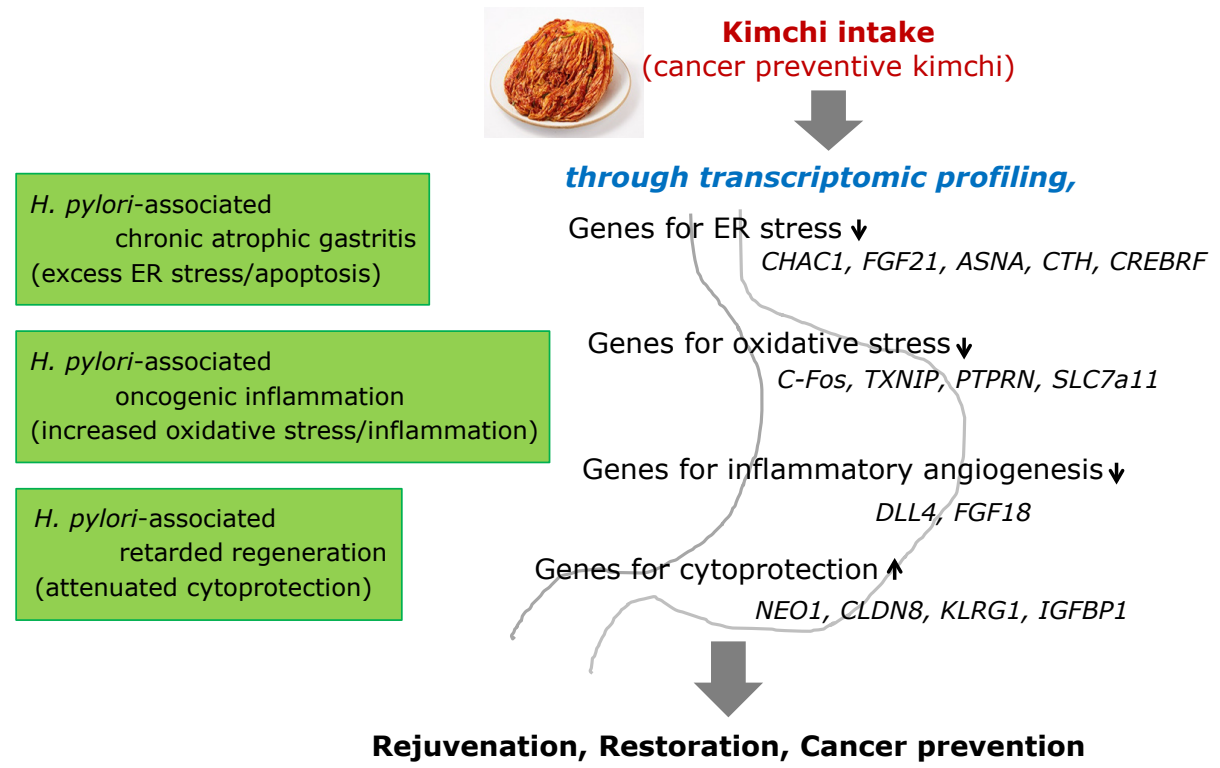

Fig. 5. Schematic presentation showing the core genes implicated in juvenating action as well as cancer preventive action of kimchi against $H$. pylori infection.

stress. ${ }^{(25,26)}$

During $H$. pylori-associated ER stress activation, in the current study, we have found core two genes, one was that CHAC 1 gene, cation transport regulator 1 , of which overexpression in gastric parietal cells may cause the $H$. pylori-induced somatic mutations, especially mutagenic p53, that contribute to the development of gastric cancer and the other was DDIT3 as target gene in ER stress relevant to H. pylori infection because these were significantly regulated with kimchi administration. ${ }^{(27-29)}$ As much as ER stress, oxidative stress contributed to $H$. pylori-carcinogenesis, which was influenced with kimchi administration. RNAseq analysis significantly showed the intervention of oxidative stress in $H$. pylori infection and mitigation of oxidative stress by kimchi. Oxidative stress relevant to pathogenesis of $H$. pylori infection and associated gastric carcinogenesis, for instance, $H$. pyloriinduced DNA damages, oncogenic activation via oxidative stress, mitochondrial damages, Nrf2-mediated autophagy, and inflammasome activation, had been proved in many publications, by which antioxidants like vitamin $\mathrm{C}$, vitamin $\mathrm{E}$, and rebamipide had been tried for either enhancing eradication rate or relieving gastric inflammation in animals and human trial. ${ }^{(30-37)}$ The fact that reactive oxygen species and reactive nitrogen species produced by $H$. pylori damage the host cells and can result in DNA damage, while $H$ pylori has wisely evolved to keep damaging response, while blunting the host's efforts to kill the bacteria led to the host response that dietary intake of kimchi can serve host to prevent gastric cancer. Conclusively, since oxidative stress in $H$. pylori infection is defined as an imbalance between excessive production of reactive oxygen and nitrogen species and depletion of antioxidative system to eliminate the reactive intermediates, kimchi significantly enriched antioxidative defense system against chronic $H$. pylori infection, imposing the importance of adaptive cellular mechanisms involved in disease blocking of $H$. pylori-associated gastric carcinogenesis. ${ }^{(38)}$

Genes for chemokine receptor family, cell cycle regulator genes, chemokine receptor activity gene, genes for regeneration and cytoprotection were identified as genes which are decreased after H. pylori infection, but significantly increased in the presence of kimchi (Fig. 3, Supplemental Fig. 2*, and Table 2), in detail, chemokine receptor family like CCR4/CCR7/ACKR4, cell cycle regulator genes like SPDYC/SPDYE4, defense response to gram-positive bacterium like ACP5/LTA/SSC5D, chemokine receptor activity gene like CCR4/ACKR4, and cytokine-cytokine receptor interaction genes like CCR4/ CCR7/TNFRSF8/LTA. Using KEGG analysis, representational transcriptomic presentations of discovered genes were shown in Fig. 3B (cytokine-cytokine receptor interaction), Fig. 3C (endocrine related-), and Fig. 3D (MAPK signaling pathway related-) were identified as signals decreased after $H$. pylori infection, but significantly up-regulated with kimchi extract administration in the presence of $H$. pylori infection. Among these, we have high concerns of genes implicated in tissue regeneration, cellular defense response, and antioxidative response including NEO1, CLDN8, KLRG1, and IGFBP-1 (Fig. 4F). Though unlimited upregulation for tissue regeneration catties risk of carcinogenesis, for instance upregulation of IGFBP-1 is associated with gastric cancer cell migration, ${ }^{(39-41)}$ retarded and deranged healing after $H$. pylori infection render vulnerability to gastric carcinogenesis. Kimchi provide optimal regenerating condition. $^{(10)}$ Next, claudin18 (CLDN18) is good marker for beneficiary role of kimchi against $H$. pylori infection since CLDN18 has been identified as important regulator in gastric cancer, as exemplified that loss of CLDN18 promotes progressive neoplasia development. ${ }^{(42-44)}$ We speculate these tight junction proteins might play to improve $H$. pylori-associated functional dyspepsia in addition to carcinogenesis. ${ }^{(45-47)}$ Conclusively, since tight junction disruption is closely associated with either dysregulation of gastric mucosal barrier or gastric carcinogenesis, ${ }^{(48)}$ kimchi afforded anticipating food factor to keep tight junction protein, CLDN18.

Neogenin 1 (NEO1) gene was not reported regarding $H$. pylori infection, it has been implicated in CNS development and nerve regeneration, ${ }^{(49,50)}$ for instance, regeneration for peripheral neuropathy with pain or spinal cord injury, ${ }^{(51-53)}$ tissue regeneration, ${ }^{(54)}$ optic nerve regeneration, ${ }^{(55)}$ renal regeneration, ${ }^{(56)}$ pancreas regeneration, ${ }^{(57)}$ and vertebrate development. ${ }^{(58)}$ though some reports showed the association between NEO1 and apoptosis. $^{(59)}$ Though not reported regarding the association 
between $H$. pylori infection and regeneration relevant to NEO 1 yet, after our study, we can speculate NEO1 can be possible target of kimchi against $H$. pylori-associated functional dyspepsia or other gastric pathologies, necessitating deeper investigation, hinted from publication by Liu et al. ${ }^{(60)}$ that repulsive guidance molecule $\mathrm{b}$ as a ligand for NEO 1 is a target for autosomal dominant polycystic kidney disease. Killer cell lectin-like receptor G1 (KLRG1) gene is drawn for the first time in $H$. pylori infection, but gene basis seems to be enough value explaining the association between $H$. pylori infection and nutrient supplementation as beneficiary contribution because KLRG1 imposed positive vaccine response against Ebola virus, ${ }^{(61)}$ skin damages, ${ }^{(62)}$ pediatric sepsis, ${ }^{(63)}$ but importantly KLRG1 impaired regulatory $\mathrm{T}$ cell competitive fitness in the gut. ${ }^{(64)}$ However, these two genes, NEO1 and NKRG1, should be further investigated, even though we have identified in the current study.

As listed in Table 1 and Table 2, individual gene can be possible biomarker denoting the contributory role against $H$. pylori infection. STRING analysis, a database that comprises established and predicted protein interactions demonstrated the strongest interactions between genes related to regulation of kimchi against $H$. pylori infection. ${ }^{(65)}$ As shown in Supplemental Fig. $1 *$ and Supplemental Fig. $2 *$, we can formulate STRING analysis as for KRGS. Though transcriptome analysis was done in the current study, kimchi is also famous for abundant probiotics with fermentation process as evidenced that nonfermented kimchi did not affect these cancer preventive outcomes compared to fermented kimchi. ${ }^{(20)}$ Kimchi is a traditional Korean fermented side-dish containing diverse strains of lactic acid bacilli such as Lactobacillus plantarum, L. acidophilus, L. curvatus, L. brevis, L. sakei, Leuconostocmesenteroides, Enterococcus faecium, and Weissellacibaria.

As the limitation of the current study, though we have several in vivo results showing beneficial outcome of kimchi intake against $H$. pylori as well as other inflammation-based cancer model, all genes identified through current transcriptome analysis should be validated or documented with additional in vitro documentation. Cell line used in the current study was AGS gastric cancer cells, but we repeated the current analysis in other cells, RGM-1 as non-transformed cells and SNU-16 cells, after which fundamental transcriptomes as shown in Fig. 4 were similar (data not shown). In order to compare current displayed results with the ones obtained using some of the standard methods for detecting differentially expressed genes (DEG) and up-/down-regulated genes, diverse analysis methods including Welch $t$-statistic, fold change, rank products, average difference (AD), weighted average difference (WAD), moderated $t$-statistic, intensity-based moderated $t$ -

\section{References}

1 Guo Y, Zhao S, Li CI, Sheng Q, Shyr Y. RNAseqPS: a web tool for estimating sample size and power for RNAseq experiment. Cancer Inform 2014; 13 (Suppl 6): 1-5.

2 Cloonan N, Grimmond SM. Transcriptome content and dynamics at singlenucleotide resolution. Genome Biol 2008; 9: 234.

3 Avital G, Hashimshony T, Yanai I. Seeing is believing: new methods for in situ single-cell transcriptomics. Genome Biol 2014; 15: 110.

4 Han KJ, Lee JE, Lee NK, Paik HD. Antioxidant and anti-inflammatory effect of probiotic Lactobacillus plantarum KU15149 derived from Korean homemade diced-radish kimchi. J Microbiol Biotechnol 2020; 30: 591-598.

5 Woo HD, Park S, Oh K, et al. Diet and cancer risk in the Korean population: a meta-analysis. Asian Pac J Cancer Prev 2014; 15: 8509-8519.

6 Kim HJ, Kim MK, Chang WK, Choi HS, Choi BY, Lee SS. Effect of nutrient intake and Helicobacter pylori infection on gastric cancer in Korea: a casecontrol study. Nutr Cancer 2005; 52: 138-146. statistic (iBMS), significance analysis of microarrays, and area under the ROC curve (AUC) has been applied, ${ }^{(66,67)}$ among which we have applied AD, WAD, and iBMS. However, we showed bar graph as shown in Supplemental Fig. 3* and Supplemental Fig. 4* either to facilitate the understanding of profiling or to avoid too many WAS arrow plots of identified data similar to volcano plots in manuscript.

Conclusively, our and other investigators strongly suggested that the diet may play a critical role in defining the final outcome of $H$. pylori infection particularly if certain intake of dietary components is continued for a long time. However, despite a recent surge in research related to the role of dietary ingredients, well-designed, large-scale clinical trials are required to give clinical benefits. In this effort, the current high throughput analysis, RNAseq transcriptome profiling, provide definite advantage and usefulness.

\section{Author Contributions}

Study concept and design: JMP and $\mathrm{KBH}$; acquisition of data: JMP, YMH, DYL, SHC analysis and statistical analysis: JMP and $\mathrm{KBH}$; interpretation of data: $\mathrm{JYO}$ and $\mathrm{KBH}$; drafting of manuscript: KBH.

\section{Acknowledgments}

This work was supported by Korea Institute of Planning and Evaluation for Technology in Food, Agriculture, Forestry and Fisheries (IPET) through High Value-added Food Technology Development Program, funded by Ministry of Agriculture, Food and Rural Affairs (MAFRA) (116015-03-1-CG000).

\section{Abbreviations}

CAG chronic atrophic gastritis

DEG differentially expressed genes

ER stress endoplasmic reticulum stress

KEGG Kyoto Encyclopedia of Genes and Genome

KRGS Kimchi Response Gene Signature

MAPK mitogen activated protein kinase

MOI multiplicity of infection

STRING Search Tool for the Retrieval of Interacting Genes/

RNAseq $\quad$ RNA sequencing

UPR unfolded protein response

\section{Conflict of Interest}

No potential conflicts of interest were disclosed.
7 Kim HJ, Chang WK, Kim MK, Lee SS, Choi BY. Dietary factors and gastric cancer in Korea: a case-control study. Int J Cancer 2002; 97: 531-535.

8 Shukla S, Park JH, Chung SH, Kim M. Ochratoxin A reduction ability of biocontrol agent Bacillus subtilis isolated from Korean traditional fermented food Kimchi. Sci Rep 2018; 8: 8039.

9 Chun BH, Kim KH, Jeon HH, Lee SH, Jeon CO. Pan-genomic and transcriptomic analyses of Leuconostoc mesenteroides provide insights into its genomic and metabolic features and roles in kimchi fermentation. Sci Rep 2017; 7: 11504.

10 Jeong M, Park JM, Han YM, et al. Dietary prevention of Helicobacter pyloriassociated gastric cancer with kimchi. Oncotarget 2015; 6: 29513-29526.

11 Kang BK, Cho MS, Park DS. Red pepper powder is a crucial factor that influences the ontogeny of Weissella cibaria during kimchi fermentation. Sci Rep 2016; 6: 28232.

12 Balic JJ, Saad MI, Dawson R, et al. Constitutive STAT3 serine 
phosphorylation promotes Helicobacter-mediated gastric disease. Am J Pathol 2020; 190: 1256-1270.

13 Ishii Y, Shibata W, Sugimori M, et al. Activation of signal transduction and activator of transcription 3 signaling contributes to Helicobacter-associated gastric epithelial proliferation and inflammation. Gastroenterol Res Pract 2018; 2018: 9050715.

14 Park JM, Han YM, Oh JY, et al. Fermented kimchi rejuvenated precancerous atrophic gastritis via mitigating Helicobacter pylori-associated endoplasmic reticulum and oxidative stress. J Clin Biochem Nutr 2021; in press.

15 Langmead B, Salzberg SL. Fast gapped-read alignment with Bowtie 2. Nat Methods 2012; 9: 357-359.

16 Quinlan AR, Hall IM. BEDTools: a flexible suite of utilities for comparing genomic features. Bioinformatics 2010; 26: 841-842.

17 Gentleman RC, Carey VJ, Bates DM, et al. Bioconductor: open software development for computational biology and bioinformatics. Genome Biol 2004; 5: R80.

18 Huang DW, Sherman BT, Tan Q, et al. The DAVID Gene Functional Classification Tool: a novel biological module-centric algorithm to functionally analyze large gene lists. Genome Biol 2007; 8: R183.

19 Kanehisa M, Furumichi M, Tanabe M, Sato Y, Morishima K. KEGG: new perspectives on genomes, pathways, diseases and drugs. Nucleic Acids Res 2017; 45: D353-D361.

20 Han YM, Kang EA, Park JM, et al. Dietary intake of fermented kimchi prevented colitis-associated cancer. J Clin Biochem Nutr 2020; 67: 263-273.

21 Liu X, Li N, Liu S, et al. Normalization methods for the analysis of unbalanced transcriptome data: a review. Front Bioeng Biotechnol 2019; 7: 358.

22 Posey JE. Genome sequencing and implications for rare disorders. Orphanet $J$ Rare Dis 2019; 14: 153.

23 Narrandes S, Xu W. Gene expression detection assay for cancer clinical use. $J$ Cancer 2018; 9: 2249-2265.

24 Baird M, Woon Ang P, Clark I, et al. The unfolded protein response is activated in Helicobacter-induced gastric carcinogenesis in a non-cell autonomous manner. Lab Invest 2013; 93: 112-122.

25 Zhu P, Xue J, Zhang ZJ, et al. Helicobacter pylori VacA induces autophagic cell death in gastric epithelial cells via the endoplasmic reticulum stress pathway. Cell Death Dis 2017; 8: 3207.

26 Akazawa Y, Isomoto H, Matsushima K, et al. Endoplasmic reticulum stress contributes to Helicobacter pylori VacA-induced apoptosis. PLoS One 2013; 8: e82322.

27 Ogawa $\mathrm{T}$, Wada Y, Takemura K, et al. CHAC1 overexpression in human gastric parietal cells with Helicobacter pylori infection in the secretory canaliculi. Helicobacter 2019; 24: e12598.

28 Wada Y, Takemura K, Tummala $\mathrm{P}$, et al. Helicobacter pylori induces somatic mutations in TP53 via overexpression of CHAC1 in infected gastric epithelial cells. FEBS Open Bio 2018; 8: 671-679.

29 Kim JM, Kim JS, Kim N, Ko SH, Jeon JI, Kim YJ. Helicobacter pylori vacuolating cytotoxin induces apoptosis via activation of endoplasmic reticulum stress in dendritic cells. J Gastroenterol Hepatol 2015; 30: 99-108.

30 Matsuoka K, Nishiumi S, Yoshida M, Kodama Y. Effects of Helicobacter pylori on the glutathione-related pathway in gastric epithelial cells. Biochem Biophys Res Commun 2020; 526: 1118-1124.

$31 \mathrm{Fu} \mathrm{L}, \mathrm{Xie} \mathrm{C}$. A lucid review of Helicobacter pylori-induced DNA damage in gastric cancer. Helicobacter 2019; 24: e12631.

32 Benitez J, Marra R, Reyes J, Calvete O. A genetic origin for acid-base imbalance triggers the mitochondrial damage that explains the autoimmune response and drives to gastric neuroendocrine tumours. Gastric Cancer 2020; 23: 52-63.

33 Sokolova O, Naumann M. Crosstalk between DNA damage and inflammation in the multiple steps of gastric carcinogenesis. Curr Top Microbiol Immunol 2019; 421: 107-137.

34 Paik JY, Lee HG, Piao JY, et al. Helicobacter pylori infection promotes autophagy through Nrf2-mediated heme oxygenase upregulation in human gastric cancer cells. Biochem Pharmacol 2019; 162: 89-97.

35 Shi Y, Wang P, Guo Y, Liang X, Li Y, Ding S. Helicobacter pylori-induced DNA damage is a potential driver for human gastric cancer AGS cells. DNA Cell Biol 2019; 38: 272-280.

36 Kumar S, Dhiman M. Inflammasome activation and regulation during Helicobacter pylori pathogenesis. Microb Pathog 2018; 125: 468-474.

37 Butcher LD, den Hartog G, Ernst PB, Crowe SE. Oxidative stress resulting from Helicobacter pylori infection contributes to gastric carcinogenesis. Cell Mol Gastroenterol Hepatol 2017; 3: 316-322.

38 Díaz P, Valenzuela Valderrama M, Bravo J, Quest AFG. Helicobacter pylori and gastric cancer: adaptive cellular mechanisms involved in disease progression. Front Microbiol 2018; 9: 5.

39 Luo C, Sun F, Zhu H, et al. Insulin-like growth factor binding protein-1 (IGFBP-1) upregulated by Helicobacter pylori and is associated with gastric cancer cells migration. Pathol Res Pract 2017; 213: 1029-1036.

40 Ustundag Y, Sahin H, Ilikhan S, Dogan BG, Kokturk F, Kar F. Helicobacter pylori eradication does not change circulating insulin-like growth factor 1 and insulin-like growth factor binding protein 3 levels in patients with and without precancerous gastric lesions. Am J Med Sci 2013; 346: 381-384.

41 Pham TM, Fujino Y, Kikuchi S, et al. A nested case-control study of stomach cancer and serum insulin-like growth factor (IGF)-1, IGF-2 and IGF-binding protein (IGFBP)-3. Eur J Cancer 2007; 43: 1611-1616.

42 Yasui W, Sentani K, Motoshita J, Nakayama H. Molecular pathobiology of gastric cancer. Scand J Surg 2006; 95: 225-231.

43 Nardone G, Compare D. Epigenetic alterations due to diet and Helicobacter pylori infection in gastric carcinogenesis. Expert Rev Gastroenterol Hepatol 2008; 2: 243-248.

44 Hagen SJ, Ang LH, Zheng Y, et al. Loss of tight junction protein claudin 18 promotes progressive neoplasia development in mouse stomach. Gastroenterology 2018; 155: 1852-1867.

45 Lee JY, Kim N, Choi YJ, et al. Expression of tight junction proteins according to functional dyspepsia subtype and sex. $J$ Neurogastroenterol Motil 2020; 26: 248-258.

46 Taki M, Oshima $\mathrm{T}$, Li $\mathrm{M}$, et al. Duodenal low-grade inflammation and expression of tight junction proteins in functional dyspepsia. Neurogastroenterol Motil 2019; 31: e13576.

47 Nakayama I, Shinozaki E, Sakata S, et al. Enrichment of CLDN18-ARHGAP fusion gene in gastric cancers in young adults. Cancer Sci 2019; 110: 1352-1363.

48 Caron TJ, Scott KE, Fox JG, Hagen SJ. Tight junction disruption: Helicobacter pylori and dysregulation of the gastric mucosal barrier. World J Gastroenterol 2015; 21: 11411-11427.

49 Dun XP, Parkinson DB. Role of Netrin-1 signaling in nerve regeneration. Int J Mol Sci 2017; 18: 491.

50 De Vries M, Cooper HM. Emerging roles for neogenin and its ligands in CNS development. J Neurochem 2008; 106: 1483-1492.

51 Schubert AL, Held M, Sommer C, Üçeyler N. Reduced gene expression of netrin family members in skin and sural nerve specimens of patients with painful peripheral neuropathies. J Neurol 2019; 266: 2812-2820.

52 Mothe AJ, Tassew NG, Shabanzadeh AP, et al. RGMa inhibition with human monoclonal antibodies promotes regeneration, plasticity and repair, and attenuates neuropathic pain after spinal cord injury. Sci Rep 2017; 7: 10529.

53 Yamashita T, Mueller BK, Hata K. Neogenin and repulsive guidance molecule signaling in the central nervous system. Curr Opin Neurobiol 2007; 17: 29-34.

54 Schlegel M, Körner A, Kaussen T, et al. Inhibition of neogenin fosters resolution of inflammation and tissue regeneration. J Clin Invest 2018; 128: 4711-4726.

55 Schnichels S, Heiduschka P, Julien S. RGMA and neogenin protein expression are influenced by lens injury following optic nerve crush in the rat retina. Graefes Arch Clin Exp Ophthalmol 2012; 250: 39-50.

56 Wang W, Reeves WB, Ramesh G. Netrin-1 increases proliferation and migration of renal proximal tubular epithelial cells via the UNC5B receptor. Am J Physiol Renal Physiol 2009; 296: F723-F729.

57 De Breuck S, Lardon J, Rooman I, Bouwens L. Netrin-1 expression in fetal and regenerating rat pancreas and its effect on the migration of human pancreatic duct and porcine islet precursor cells. Diabetologia 2003; 46: 926-933.

58 Shin GJ, Wilson NH. Overexpression of repulsive guidance molecule (RGM) a induces cell death through Neogenin in early vertebrate development. $\mathrm{J} \mathrm{Mol}$ Histol 2008; 39: 105-113.

59 Tassew NG, Mothe AJ, Shabanzadeh AP, et al. Modifying lipid rafts promotes regeneration and functional recovery. Cell Rep 2014; 8: 1146-1159.

60 Liu J, Wang W, Liu M, et al. Repulsive guidance molecule b inhibits renal cyst development through the bone morphogenetic protein signaling pathway. Cell Signal 2016; 28: 1842-1851.

61 Bowyer G, Sharpe H, Venkatraman N, et al. Reduced Ebola vaccine 
responses in $\mathrm{CMV}^{+}$young adults is associated with expansion of $\mathrm{CD} 7^{+} \mathrm{KLRG}^{+}$T cells. J Exp Med 2020; 217:e20200004.

62 Seidel JA, Vukmanovic-Stejic M, Muller-Durovic B, et al. Skin resident memory $\mathrm{CD}^{+} \mathrm{T}$ cells are phenotypically and functionally distinct from circulating populations and lack immediate cytotoxic function. Clin Exp Immunol 2018; 194: 79-92.

63 Li Y, Li Y, Bai Z, Pan J, Wang J, Fang F. Identification of potential transcriptomic markers in developing pediatric sepsis: a weighted gene coexpression network analysis and a case-control validation study. J Transl Med 2017; 15: 254.

64 Meinicke H, Bremser A, Brack M, Schrenk K, Pircher H, Izcue A. KLRG1 impairs regulatory T-cell competitive fitness in the gut. Immunology 2017; 152: $65-73$.

65 Yang M, Li H, Li Y, Ruan Y, Quan C. Identification of genes and pathways associated with MDR in MCF-7/MDR breast cancer cells by RNA-seq analysis. Mol Med Rep 2018; 17: 6211-6226.

66 Silva-Fortes C, Amaral Turkman MA, Sousa L. Arrow plot: a new graphical tool for selecting up and down regulated genes and genes differentially expressed on sample subgroups. BMC Bioinformatics 2012; 13: 147.

67 Kadota K, Nakai Y, Shimizu K. A weighted average difference method for detecting differentially expressed genes from microarray data. Algorithms Mol Biol 2008; 3: 8 .

This is an open access article distributed under the terms of the Creative Commons Attribution-NonCommercial-NoDerivatives License (http://creativecommons.org/licenses/by-nc-nd/4.0/). 